Hydrol. Earth Syst. Sci., 16, 4079-4099, 2012

www.hydrol-earth-syst-sci.net/16/4079/2012/

doi:10.5194/hess-16-4079-2012

(c) Author(s) 2012. CC Attribution 3.0 License.

(c) (i)

\title{
COSMOS: the COsmic-ray Soil Moisture Observing System
}

\author{
M. Zreda ${ }^{1}$, W. J. Shuttleworth ${ }^{1}$, X. Zeng ${ }^{2}$, C. Zweck ${ }^{1}$, D. Desilets ${ }^{3}$, T. Franz ${ }^{1}$, and R. Rosolem ${ }^{1}$ \\ ${ }^{1}$ Department of Hydrology and Water Resources, University of Arizona, Tucson, AZ 85721, USA \\ ${ }^{2}$ Department of Atmospheric Sciences, University of Arizona, Tucson, AZ 85721, USA \\ ${ }^{3}$ Hydroinnova LLC, Albuquerque, NM 87106, USA \\ Correspondence to: M. Zreda (marek@hwr.arizona.edu)
}

Received: 18 March 2012 - Published in Hydrol. Earth Syst. Sci. Discuss.: 4 April 2012

Revised: 20 September 2012 - Accepted: 7 October 2012 - Published: 7 November 2012

\begin{abstract}
The newly-developed cosmic-ray method for measuring area-average soil moisture at the hectometer horizontal scale is being implemented in the COsmic-ray Soil Moisture Observing System (or the COSMOS). The stationary cosmic-ray soil moisture probe measures the neutrons that are generated by cosmic rays within air and soil and other materials, moderated by mainly hydrogen atoms located primarily in soil water, and emitted to the atmosphere where they mix instantaneously at a scale of hundreds of meters and whose density is inversely correlated with soil moisture. The COSMOS has already deployed more than 50 of the eventual 500 cosmic-ray probes, distributed mainly in the USA, each generating a time series of average soil moisture over its horizontal footprint, with similar networks coming into existence around the world. This paper is written to serve a community need to better understand this novel method and the COSMOS project. We describe the cosmic-ray soil moisture measurement method, the instrument and its calibration, the design, data processing and dissemination used in the COSMOS project, and give example time series of soil moisture obtained from COSMOS probes.
\end{abstract}

\section{Introduction}

Although the total amount of water stored in soil is much less than that stored in oceans, fluxes of water into and out of soils can be large, making soil water important in the exchange of matter and energy between the solid earth and the atmosphere. Evapotranspiration, infiltration and runoff depend on soil wetness, as does the sensible heat flux from the surface and the heat stored in soils. Soils provide nutrients for the biosphere, and soil water is also important in biogeochemical cycles. Soil water controls forcings and feedbacks between the subsurface and the atmosphere, thereby giving it a significant role in moderating weather and climate, and in controlling the partitioning between surface runoff and infiltration on one hand, and evapotranspiration on the other. Because of soil moisture's importance for so many different fields, it has received much attention, from theoreticians and modelers and from experimenters and observers. However, its role in the environment is among the least well understood because area-representative soil moisture is difficult to measure at the intermediate scale of $\sim 1 \mathrm{~km}$ that is relevant to land-surface and atmospheric models.

Many methods measure soil moisture at a point (Robinson et al., 2008). However, point measurements share a critical shortcoming; they are not representative of the surrounding area because soil moisture is spatially heterogeneous over a range of length scales (e.g., Western and Blöschl, 1999; Entin et al., 2000; Famiglietti et al., 2008). An example of such heterogeneity within a circular area with a diameter of ca. $400 \mathrm{~m}$ is shown in Fig. 1. Individual soil moisture measurements range from $0.06 \mathrm{~m}^{3} \mathrm{~m}^{-3}$ to $0.37 \mathrm{~m}^{3} \mathrm{~m}^{-3}$, and averages of individual profiles range from $0.08 \mathrm{~m}^{3} \mathrm{~m}^{-3}$ to $0.27 \mathrm{~m}^{3} \mathrm{~m}^{-3}$. Such heterogeneity precludes meaningful assessment of area-representative soil moisture from a single point or a single profile. However, area-average soil moisture of a desired precision is attainable if enough point measurements are made over the area. For the soil moisture distribution shown in Fig. 1, a $0.03 \mathrm{~m}^{3} \mathrm{~m}^{-3}$ precision would require more than 40 point measurements (more than 10 profiles). Consequently, such assessments, while technically possible (Famiglietti et al., 1999, 2008; Bogena et al., 2010), are difficult, expensive and often impractical (Western et al., 2002). As a result, large-scale and long-term soil moisture data for

Published by Copernicus Publications on behalf of the European Geosciences Union. 
atmospheric and other applications are practically impossible to obtain using point measurement techniques.

At the other end of the spatial scale, satellite microwave sensing can provide integrated values of near-surface soil moisture over hundreds to thousands of square kilometers (Njoku and Entekhabi, 1996). While satellite retrievals of soil moisture have the distinct advantage of global coverage, they suffer from several limitations (Entekhabi et al., 2004), including a shallow vertical penetration depth of millimeters to centimeters, limited capability to penetrate vegetation or snow, sensitivity to surface roughness, discontinuous temporal coverage, and the short life span and high cost of satellite missions. The critical gap between point measurements and satellite retrievals at the intermediate scale of meters to kilometers can be filled by recently-developed methods for measuring average soil moisture along lines (Steele-Dunne et al., 2010) and over areas using either a single instrument (Larson et al., 2008; Zreda et al., 2008) or a distributed-sensor network (Bogena et al., 2010).

Here, we describe the COsmic-ray Soil Moisture Observing System (the COSMOS), a continental-scale network consisting of instruments that provide intermediate scale average soil moisture by measuring cosmic-ray neutrons above the land surface (Zreda et al., 2008). The COSMOS is designed to improve the availability of continental-scale soil moisture measurements by ultimately deploying a network of 500 COSMOS probes across the USA. Each will measure average soil water content within a diameter of a few hectometers and to a depth of a few decimeters (Zreda et al., 2008), thereby averaging soil moisture heterogeneities such as those shown in Fig. 1.

Section 2 describes the cosmic-ray method for measuring area-average soil moisture; Sect. 3 discusses the COSMOS and its components as well as some recent observational results. Building on the short articles of Zreda et al. (2008) and Desilets et al. (2010), this paper presents a much more comprehensive discussion of scientific background and technical details at a level that is intended to be accessible to the diverse communities interested in this novel method and the data from the COSMOS project.

\section{Cosmic-ray soil moisture method}

Cosmic rays were discovered by Victor Hess (1912), who was awarded the Nobel Prize in Physics in 1936 for this discovery (Carlson, 2012). Robert Millikan ascribed the phenomenon to microwaves emanating from galactic sources, and thus applied the misnomer "cosmic rays". It was later shown (Compton and Eastman, 1935) that the ionization observed by Hess was caused by secondary radiation, and that the primary radiation consisted of electrically charged particles impinging on the atmosphere. Neutrons, gamma rays, muons and several short-lived subatomic particles have since been identified in the secondary cosmic-ray flux.

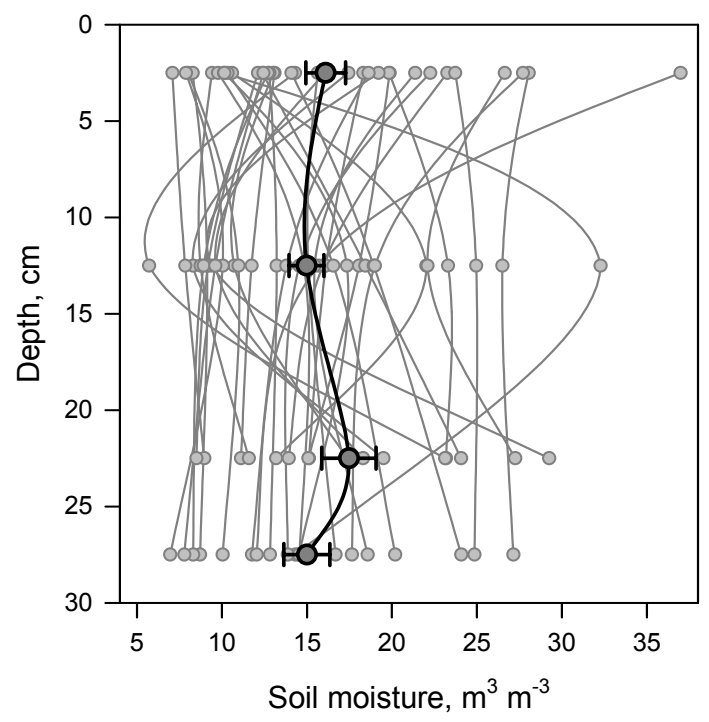

Fig. 1. Variations in soil moisture profiles at the horizontal scale of $400 \mathrm{~m}$ at the COSMOS site in the San Pedro River valley, Arizona. Thirty five profiles (gray lines) of three to four samples each (gray symbols) were averaged to give the area-average profile (black symbols and connecting line). Undisturbed soil cores were collected down to $30 \mathrm{~cm}$ and divided into six sections on which moisture content was measured by the standard oven-drying method. Gray points are in the middle of the $5 \mathrm{~cm}$ intervals.

Theoretical work more than half a century ago showed that the intensity of low-energy cosmic-ray neutrons depends on the chemical composition of the material, and particularly on its hydrogen content (Fermi, 1938; Bethe et al., 1940). Measurements (Hendrick and Edge, 1966) showed that the intensity of "fast" neutrons above the ground depends on water content of the ground (Fig. 2). At that time cosmic-ray physicists considered this noise in the measurement of high-energy cosmic-ray neutrons that had to be minimized or removed. However, to hydrologists today, this is the signal that carries information about the amount of water near the Earth's surface.

The first scientists who attempted to use cosmic rays to measure soil moisture (Kodama et al., 1985) and snow pack (Kodama et al., 1979) placed their detectors in the soil or snow. Such placement gave a small measurement volume, on the order of decimeters, dictated by the short mass distance that fast neutrons can traverse in a medium, i.e., tens of grams of water or soil per square centimeter of area perpendicular to neutron movement, which is equivalent to tens of centimeters in either medium (note that units of $\mathrm{g} \mathrm{cm}^{-2}$ are used by cosmic-ray physicists to describe the amount of mass shielding or the travel/penetration depth). Zreda et al. (2008) demonstrated that placing a neutron detector above the ground allowed measurement of average soil moisture over a horizontal footprint of hectometers (equivalent to tens of grams of air) and to a depth of decimeters (equivalent to 


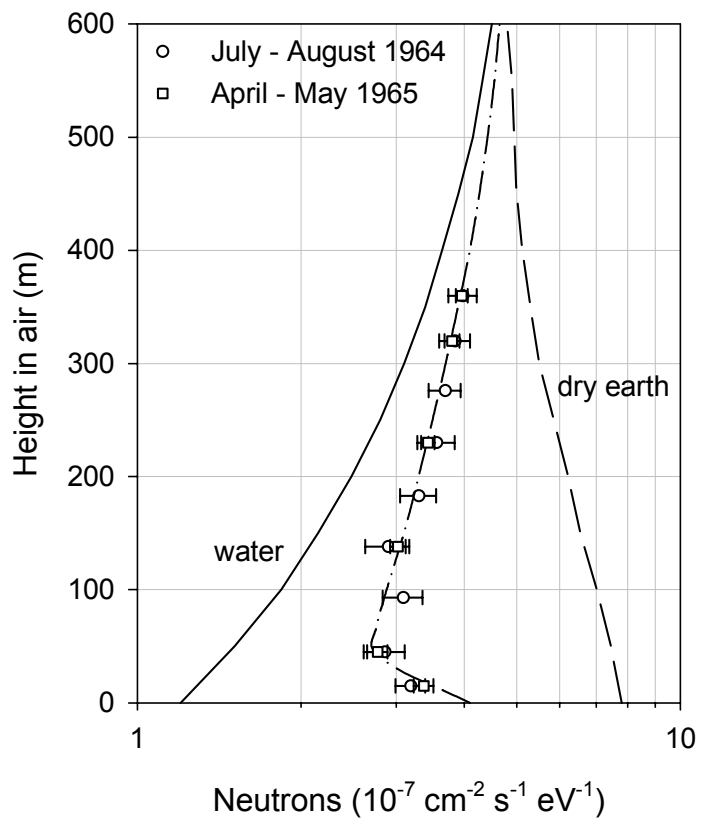

Fig. 2. Distribution of "fast" neutrons above the Earth's surface showing strong dependence on surface moisture. Circles and squares are measurements on a radio tower. A theoretical model that best fits the data (dash-dotted line) suggests a soil moisture of $0.03 \mathrm{~m}^{3} \mathrm{~m}^{-3}$ to $0.05 \mathrm{~m}^{3} \mathrm{~m}^{-3}$. Replotted from Hendrick and Edge (1966).

tens of grams of soil). Similarly, Desilets et al. (2010) placed a neutron detector above a snow surface and measured average snow water equivalent over a comparably large horizontal footprint. Detector placement above the surface is critical to cosmic-ray probes because it allows one to take advantage of mixing of neutrons in the atmosphere at the scale of hundreds of meters, which results in a large measurement footprint.

\subsection{Production of cosmic-ray fast neutrons on Earth}

Primary cosmic rays can be of galactic or solar origin, but it is mainly the galactic cosmic rays that have enough energy to create secondary particle cascades that penetrate to ground level. It is these that are important when measuring soil moisture. Secondary cosmic-ray neutrons can be categorized as follows (Fig. 3): (a) high-energy cascade neutrons, with energy on the order of $\mathrm{GeV}$, generated by primary protons and heavier atoms splitting atmospheric nuclei into particles that include neutrons; (b) fast neutrons, with energy on the order of $1 \mathrm{MeV}$, generated by high-energy neutrons colliding with nuclei leading to "evaporation" of fast neutrons; and (c) low-energy thermal $(0.025 \mathrm{eV})$ and epithermal $(>0.5 \mathrm{eV})$ neutrons, produced by moderation of fast neutrons through collisions with atomic nuclei.

Protons make up more than $90 \%$ of the incoming galactic cosmic rays while alpha particles and heavier nuclei make

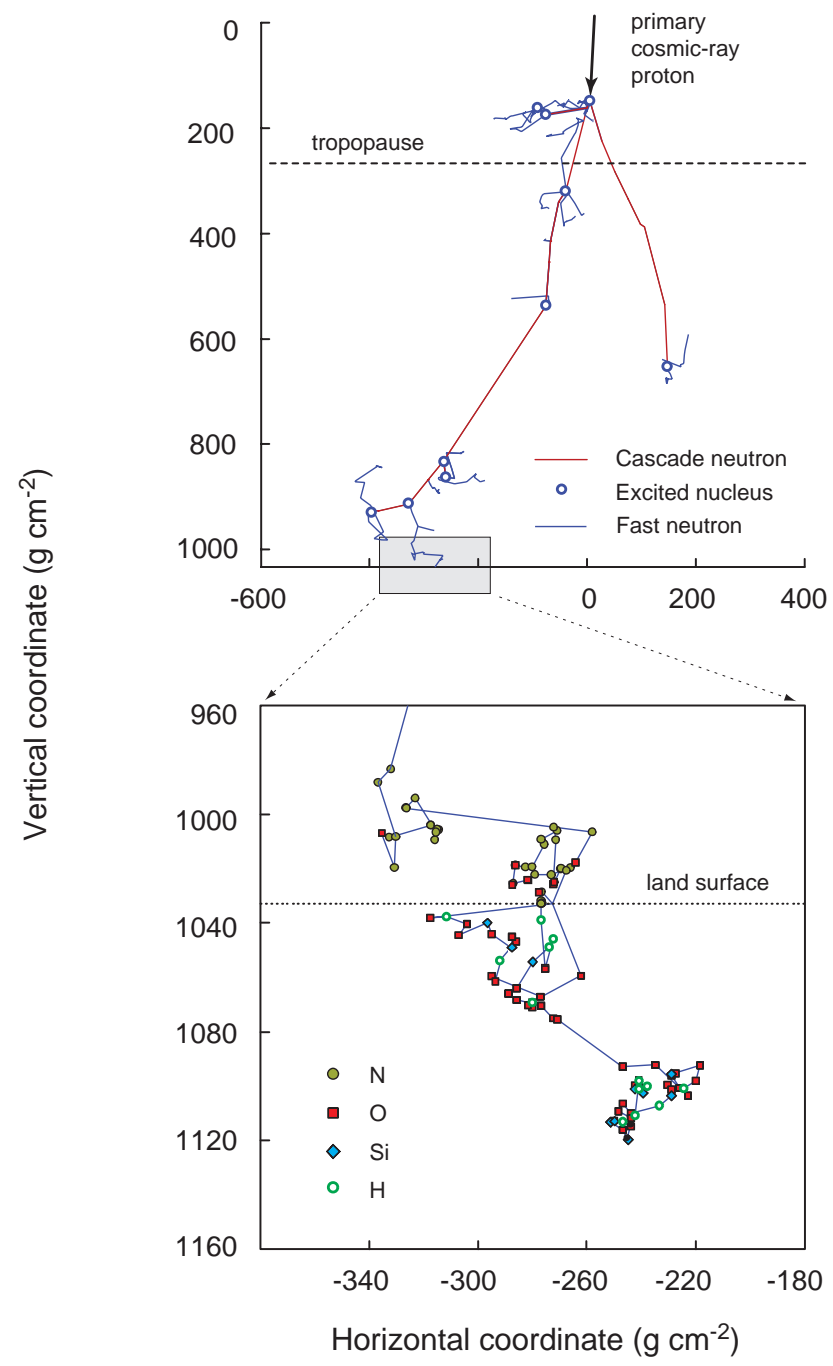

Fig. 3. Cascade of high-energy secondary neutrons, and production and scattering of fast neutrons in air and ground (modified from Fig. 1 in Desilets et al., 2010).

up most of the remainder; neutrons are absent because of their short life span ( $15 \mathrm{~min}$; Anton et al., 1989). Being charged particles, protons have to penetrate the solar magnetic field and the geomagnetic field. Protons that are energetic enough to travel through these magnetic fields enter the atmosphere where they collide with and disintegrate nuclei to create energetic secondary particles, which in turn produce tertiary particles in a chain reaction. Because neutron energy decreases with every collision, disintegration of nuclei becomes progressively less likely as the cascade propagates through the atmosphere. Instead, a high-energy neutron can enter a nucleus and excite it to an unstable energy level. To return to a stable energy level, the nucleus emits a fast neutron in a process called evaporation (analogous to evaporation of water molecules from the surface of water). These neutrons are important in the determination of water at the 
Earth's surface because they are easily moderated by hydrogen atoms (Fig. 3).

The fast neutrons that are produced in air, vegetation and soil travel in all directions and penetrate a few tens of $\mathrm{g} \mathrm{cm}^{-2}$ of matter (in air this corresponds to a few hundred meters but in soils to a few tens of $\mathrm{cm}$ ) before they are thermalized. They travel within and between air and soil, and in this way an equilibrium concentration of neutrons is established in each of the two media; that equilibrium is achieved nearly instantaneously because fast neutrons have velocities of tens to thousands of kilometers per second, depending on energy (Glasstone and Edlund, 1952, Eq. 3.19.1 on p. 38), and the fast neutron slowing down time is essentially instantaneous, on the order of $10^{-4} \mathrm{~s}$ (Glasstone and Edlund, 1952, Table 6.147 on p. 184). The equilibrium concentration of fast neutrons depends on two factors: the production rate of fast neutrons, which is known (implicitly, via local calibration; see Eq. 4 and Sect. 2.5), and the efficiency of moderating of fast neutrons, which depends on the stopping power of the medium and thus on its hydrogen content (see Sect. 2.2). Consequently, by measuring the fast neutron intensity the hydrogen content of the medium can be inferred.

The fast neutron source function, or the production rate, depends on the incoming high-energy neutron intensity (as described above) and the chemical composition of the medium. More fast neutrons are produced per incident highenergy neutron from heavier elements than from lighter elements because of an increased probability of producing more than one fast neutron per incident high-energy neutron. The production rate of fast neutrons increases as $A^{2 / 3}$, where $A$ is the atomic mass number (Geiger, 1956), and the formula holds at different latitudes and pressures (Simpson and Uretz, 1953). Thus, soils with high concentrations of potassium $(A=39)$, calcium (40) and iron (55) have higher production rates of fast neutrons than soils composed mainly of aluminium (27), silicone (28) and sodium (23). These production rates are also higher than in water, comprising oxygen (16) and hydrogen (1), or in air, mainly comprising nitrogen (14) and oxygen (16). Due to this effect production rates of fast neutrons depend on soil mineral chemistry, and also on soil moisture content.

Intensity of high-energy neutrons varies in space and time (Desilets and Zreda, 2003). Spatial variations are due to the variable strength of the geomagnetic field (Fig. 1 in Desilets et al., 2006) and variable atmospheric pressure. It increases from a minimum at the geomagnetic equator, where the field is horizontal, towards the poles, where the field is vertical. The intensity also decreases by approximately a factor of two for each additional $100 \mathrm{hPa}$ of pressure as the nucleonic cascade travels through the air and interacts with atmospheric nuclei. It decreases similarly with mass shielding depth in Earth's solids and liquids. Spatial variations in cosmic-ray intensity can be computed for any location (latitude, longitude and elevation) relative to any reference location (Desilets and Zreda, 2003; Desilets et al., 2006).

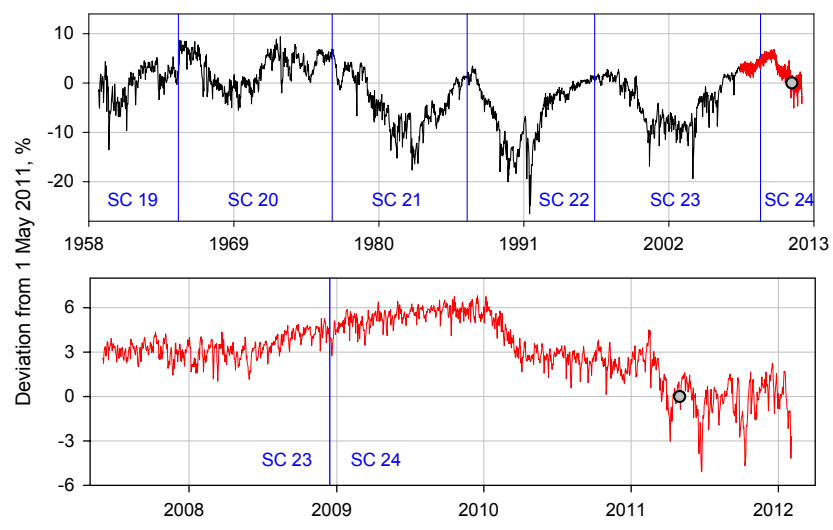

Fig. 4. Variations in time of the high-energy cosmic-ray neutrons measured with a neutron monitor (Simpson, 2000) at Jungfraujoch, Switzerland (data from Neutron Monitor Data Base, http://www. nmdb.eu/nest/search.php, accessed on 2 February 2012), and reported as relative difference from the value on 1 May 2011 ((valuevalue1may11)/value1may11). The data shown in black have a resolution of ten days, while those in red have a resolution of one day. The lower panel and the red line in the upper panel show the data between 2007, when the longest continuously running COSMOS probe was installed, and today. The blue lines separate solar cycles (SC). Solar cycles are on average $11 \mathrm{yr}$ long, but vary from nine years to $13 \mathrm{yr}$.

Temporal variations in cosmic-ray intensity are due to many factors, two being most important, namely solar activity and barometric pressure changes. During high solar output (a solar maximum), the stronger solar magnetic field deflects a greater fraction of the galactic protons away from the Earth, and the galactic cosmic-ray intensity on Earth is reduced; this is the familiar 11-yr solar cycle (Fig. 4). Conversely, during low solar activity the weaker solar magnetic field allows more galactic protons and the galactic cosmicray intensity on Earth is higher. Shorter-term fluctuations have a similar effect (albeit of smaller amplitude) on the cosmic-ray intensity. Changes in the shape of the geomagnetic field which occur on the time scales of years to decades are of secondary importance to temporal variations in the cosmic-ray intensity. Temporal variations caused by solar and geomagnetic fields are measured directly with the instrument called a neutron monitor (Simpson, 2000), which is sensitive to high-energy secondary neutrons but insensitive to local environmental factors such as soil moisture.

The mass thickness (or barometric pressure) of the atmosphere varies in time with changing weather conditions, and this affects the amount of atmospheric shielding. Changes in near-ground cosmic-ray neutron intensity are inversely proportional to changes in local barometric pressure, which is a good proxy for mass shielding (Eq. 1 in Desilets et al., 2006). To account for these changes, each COSMOS probe includes a pressure sensor. 


\subsection{Moderation of fast neutrons in soils}

Fast neutrons that are produced in the atmosphere, water, vegetation and soil undergo elastic collisions with nuclei, lose energy and are eventually absorbed in inelastic nuclear collisions. This process of moderation (slowing or stopping) of neutrons depends on three factors that together define the neutron stopping power of a material (Table 1): (a) the probability of scattering by different elements, characterized by their microscopic (elemental) scattering cross-sections, and, in combination with (c) below, the resultant macroscopic scattering cross-section of the material; (b) the energy loss per collision or, inversely, the number of collisions necessary to moderate a fast neutron; and (c) the number of nuclei of different elements, or the elemental concentration.

The first factor, the elemental scattering cross-section or probability of scattering, varies with no apparent regularity between 1 barn $\left(1\right.$ barn $\left.=10^{-24} \mathrm{~cm}^{2}\right)$ for sulfur and 180 barns for gadolinium. For the ten elements that count most for scattering of neutrons in natural soils (Table 1), the elastic scattering cross-sections vary from 2 barns for aluminium to 22 barns for free hydrogen.

The second factor, the logarithmic decrement of energy per collision (or lethargy, Glasstone and Edlund, 1952), characterizes the efficiency of each collision on average in moderating a neutron. Hydrogen is by far the most efficient element. On average, it takes only 18 collisions with hydrogen to thermalize a fast neutron (logarithmic decrement of energy per neutron collision is 1 and the number of log decrements is 17.5). The next most efficient element among those found in rocks, albeit in low quantities, is boron with 103 collisions and a logarithmic decrement of 0.174 . There is a clear pattern here: As the atomic mass increases, the number of collisions increases and the decrement of energy decreases. The reason for this regularity is that the mass of nuclei is approximately a multiple of the mass of neutron. When a neutron hits a large nucleus, for example iron with 26 protons and 30 neutrons, it bounces off and maintains most of its energy (analogous to a billiard ball bouncing off the cushion) and approximately 505 collisions with iron are needed to convert a fast neutron to a thermal neutron (Table 1). On the other hand, when a neutron hits the hydrogen nucleus, which has one proton and no neutrons, it will transfer much of its energy to the proton (much like a billiard ball that hits another). Consequently, fewer collisions with hydrogen are needed to slow a fast neutron to the thermal level. The scattering cross-section and the logarithmic decrement, when multiplied together, define the "stopping power" of an element (Table 1). Hydrogen has by far the highest stopping power (22.01), the next most important element, gadolinium, has a stopping power which is a tenth of this (2.28), and the remaining elements have fractions of that of gadolinium.

The third factor is the number of atoms of an element per unit mass of material. This is proportional to the concentration of the element and to the inverse of its mass
Table 1. Nuclear properties of ten elements contributing most to macroscopic scattering cross-section in terrestrial rocks. Key: $A-$ atomic mass $\left(\mathrm{g} \mathrm{mole}^{-1}\right) ; \sigma$ - elastic scattering cross-section (barns; 1 barn $=10^{-24} \mathrm{~cm}^{2}$ ); $\mathrm{H}$ from Fig. 4.6 in Krane, 1988); other elements from Table 1 in Sears (1992); NC - number of collisions to thermalize a 1-2 MeV neutron (calculated using Eq. 12.8 in Krane, 1988); $\xi$ - average log decrement of energy per neutron collision (or lethargy); SP - elemental stopping power (computed as $\xi \cdot \sigma_{\mathrm{sc}}$ ) in $\mathrm{cm}^{-1} ; C$ - concentration, in ppm, of elements in dry "average rock" (see text; the concentrations are not normalized to add up to $100 \%)$.

\begin{tabular}{lllrcrr}
\hline Element & $A$ & $\sigma_{\mathrm{sc}}$ & $\mathrm{NC}$ & $\xi$ & $\mathrm{SP}$ & $C$ \\
\hline $\mathrm{H}$ & 1.0079 & 22.02 & 18 & 1.000 & 22.016 & - \\
$\mathrm{O}$ & 15.9994 & 4.232 & 149 & 0.120 & 0.508 & 487875 \\
$\mathrm{C}$ & 12.011 & 5.551 & 113 & 0.158 & 0.875 & 87638 \\
$\mathrm{Si}$ & 28.0855 & 2.167 & 257 & 0.070 & 0.151 & 281367 \\
$\mathrm{Na}$ & 22.9898 & 3.28 & 211 & 0.085 & 0.277 & 23206 \\
$\mathrm{Ca}$ & 40.078 & 2.83 & 364 & 0.049 & 0.139 & 70963 \\
$\mathrm{Al}$ & 26.9815 & 1.503 & 247 & 0.072 & 0.109 & 58015 \\
$\mathrm{Fe}$ & 55.847 & 11.62 & 505 & 0.035 & 0.411 & 28980 \\
$\mathrm{Mg}$ & 24.305 & 3.71 & 223 & 0.080 & 0.297 & 13436 \\
$\mathrm{~K}$ & 39.0983 & 1.96 & 355 & 0.050 & 0.099 & 19137 \\
\hline
\end{tabular}

number. Abundant and/or light elements such as hydrogen are most important, whereas rare and/or heavy elements such as gadolinium are insignificant.

The three factors can be combined to give a parameter that indicates the fraction of the total moderating (stopping, slowing down) power of a material that is due to a specific element. As an example, in Fig. 5 we created four hypothetical rocks, granite, basalt, limestone and quartzite, by using chemical compositions of multiple rocks in each group, added different amounts of water, and computed the fractional stopping power of the ten most important elements. In dry conditions (with no water), oxygen accounts for approximately three-quarters of the stopping power of the rocks (Fig. 5a). However, when water is added, even in small quantities, hydrogen rapidly accounts for most of the stopping power of the mixture, regardless of the chemical makeup of the rock. When water content is only $0.01 \mathrm{~kg} \mathrm{~kg}^{-1}$, hydrogen accounts for half of the stopping power (Fig. 5b), at $0.03 \mathrm{~kg} \mathrm{~kg}^{-1}$ it accounts for four-fifths (Fig. 5c), and at $0.10 \mathrm{~kg} \mathrm{~kg}^{-1}$ for more than nine-tenths (Fig. 5d). The dominance of hydrogen in the moderation of fast neutrons is the basis of the cosmic-ray soil moisture measurement method.

\subsection{Measuring soil moisture using cosmic-ray fast neutrons}

The equilibrium concentration of fast neutrons measured above the ground depends on how many neutrons are produced and how many are downscattered to lower energies, and can be expressed as (Glasstone and Edlund, 1952) 

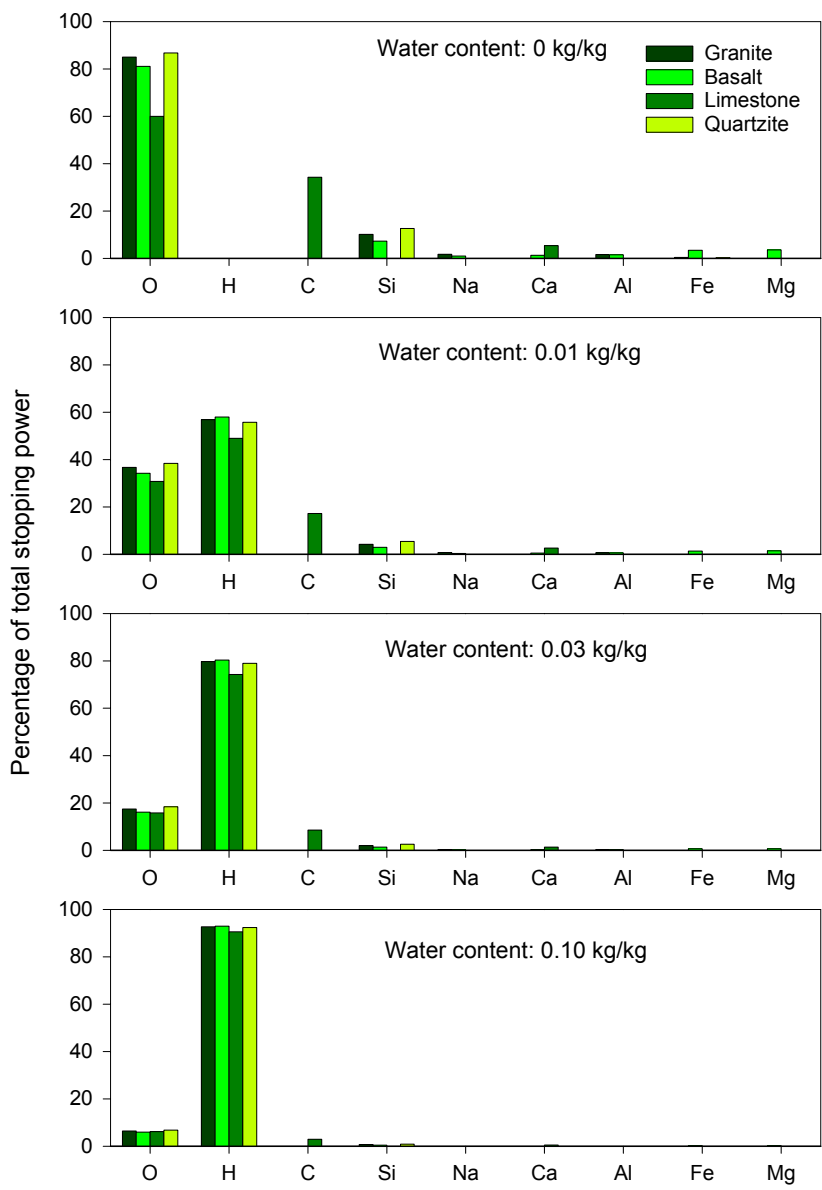

Fig. 5. Fractions of total stopping power in four common rocks contributed by the eight most important rock-forming elements and hydrogen, at four water contents. In all rocks, hydrogen becomes the most important moderating element at water content as low as $0.01 \mathrm{~kg} \mathrm{~kg}^{-1}$.

$$
\begin{aligned}
\phi & =\frac{Q}{E \cdot \mathrm{SP}} \\
\phi & =\frac{Q}{E \cdot \sum_{i=1}^{n}\left(N_{i} \cdot \sigma_{i} \cdot \xi_{i}\right)} \\
\phi & =\frac{Q}{E \cdot\left(N_{\mathrm{h}} \cdot \sigma_{\mathrm{h}} \cdot \xi_{\mathrm{h}}+\sum_{i=2}^{n}\left(N_{i} \cdot \sigma_{i} \cdot \xi_{i}\right)\right)}
\end{aligned}
$$

where $\phi$ is the intensity of neutrons of energy $E ; Q$ is the neutron source intensity (the number of fast neutrons produced); and SP is the macroscopic stopping power of a material, computed (Eq. 2) from the number of atoms $N$ of all elements from $i=1$ to $i=n$ ( $n$ is the number of elements in soil that are important for scattering neutrons; see Table 1 and Fig. 5), the elemental scattering cross-section $\sigma$ and the elemental logarithmic energy decrement $\xi$ (see Table 1). Because $Q$ is known (implicitly) from calibration on local soil or theoretical computation, and $\phi$ is measured, the equation can be solved for SP, and because SP depends almost entirely on the presence of hydrogen (Table 1, Fig. 5), the number of atoms $N_{\mathrm{h}}$ of hydrogen in soil can be inferred (Eq. 3). In Eq. (3) the macroscopic stopping power was separated into the term due to hydrogen and that due to all other elements (the sum from $i=2$ to $i=n$ ). Equation (3) applies if other sources of hydrogen, for example vegetation, are constant or negligible. Otherwise, Eq. (3) should be modified by either adding hydrogen source terms $N$ or by modifying the neutron intensity term $\phi$.

Fast neutrons are also produced and moderated in the atmosphere. Because the chemical composition of air is almost constant, the production rate is nearly constant. However, the small variations in the water vapor content increase the macroscopic scattering cross-section of the air and thus decrease the fast neutron intensity. This effect is significant, up to a few percent between dry air and saturated air, resulting in considerable changes in the partial pressure of the atmospheric water vapor in time and space; hence, a correction for atmospheric moisture content (Sect. 2.4.3) should be included in the conversion of measured neutron intensity to soil moisture.

The effects of location and soil chemistry are accounted for by making a local calibration to define the relationship between the fast neutron intensity, $\phi$ (normalized for variations in pressure, atmospheric water vapor, and solar activity), and soil moisture, SM. Equation (A1) in Desilets et al. (2010) captures the main behavior of the calibration function:

$\mathrm{SM}=\frac{a_{0}}{\phi / \phi_{0}-a_{1}}-a_{2}$

where $\phi_{0}$ is the neutron intensity in air above dry soil (obtained by calibration, see Sect. 2.5), and $a_{0}, a_{1}$ and $a_{2}$ are fitted constants that define the shape of the calibration function. For silica soil, computations using the neutron transport code MCNPX (standing for Monte Carlo NParticle eXtended) (Pelowitz, 2005) gave the fitting constants: $a_{0}=0.0808, a_{1}=0.372$, and $a_{2}=0.115$ (Desilets et al., 2010). As noted by Desilets et al. (2010), the equation works only for moisture levels greater than $0.02 \mathrm{~kg} \mathrm{~kg}^{-1}$, but because of water in mineral lattices and in organic matter that is present in most soils (Sect. 2.3.1.), the equation should be applicable to most soils.

\subsection{Other sources of water}

Other sources of hydrogen exist in and near soils. They include lattice water, atmospheric water vapor, snow cover, and water in and on vegetation. This additional hydrogen should be taken into account when converting neutron intensity to soil moisture. 


\subsubsection{Lattice water}

MCNPX modeling results show that the shape of the calibration function is similar for different chemical compositions (Zreda et al., 2008), except for an offset caused by differing lattice water, thus suggesting the existence of a universal calibration function (Franz et al., 2012b). Lattice water is present in the crystal lattice of various minerals, such as biotite, hornblende, gypsum or clay minerals. It is a material property and should be constant in time (except on time scales of chemical weathering - thousands of years - which are irrelevant here). Measurements on samples from the COSMOS sites (Table 2) show that lattice water varies considerably in space, from near zero in soils composed of quartz (for example, site Austin Cary, Florida) to more than $0.2 \mathrm{~g} \mathrm{~g}^{-1}$ on those developed on volcanic ash (site Island Dairy, Hawaii).

Lattice water affects how fast neutrons interact with the soil, which makes it important for two aspects of the cosmicray method: it reduces the measurement depth (Sect. 2.5.2) and it changes the calibration function's position and slope (Sect. 2.6.1). Fortunately, lattice water can easily be measured and implemented in computational algorithms, and the universal calibration function can be constructed using soil chemistry and the site location (Franz et al., 2012b).

\subsubsection{Water in soil organic matter}

Soil organic matter contains hydrogen and thus has a similar effect to that of lattice water. Like lattice water, its concentration in a soil should be approximately constant in time. The amount of organic $\mathrm{C}$ in soils from the COSMOS sites (Table 2) ranges from near zero in mineral soils (for example, Desert Chaparral, California) to $8.1 \mathrm{wt} \%$ in organic-rich soils in forests (the Howland site, Maine). The amount of $\mathrm{H}_{2} \mathrm{O}$ equivalent that is locked in organic matter is roughly equal to the weight percent of $\mathrm{C}$, and is approximately half of that in lattice water. Hydrogen in organic matter becomes important for the calibration function when organic $\mathrm{C}$ exceeds $\sim 1 \%$ by weight (Table 2 ).

\subsubsection{Atmospheric water vapor, vegetation and surface water}

Vegetation water, atmospheric water vapor and any other source of hydrogen have a similar effect to that of lattice water, and they can be handled either by pooling the different sources into one equivalent reservoir of moisture and then partitioning the computed total moisture into components, as is done with lattice water (Franz et al., 2012b), or by correcting measured neutron intensity and then doing computations on the corrected values, as is done with atmospheric water vapor (Sect. 3.3.2).

Snow, and also any surface water, is an important source of water at the land surface. It depresses the neutron intensity, and snow in an amount that exceeds $6 \mathrm{~cm}$ of water equivalent
Table 2. Lattice water and organic $\mathrm{C}$ in soil samples from the COSMOS sites. Lattice water was measured using the gravity method, and soil organic $\mathrm{C}$ was computed from $\mathrm{CO}_{2}$ measured using coulometry and total $\mathrm{C}$ measured using infrared technology. All measurements were done at Actlabs, Ontario, Canada.

\begin{tabular}{|c|c|c|c|c|}
\hline Site & $\begin{array}{r}\text { Latitude } \\
\left({ }^{\circ} \mathrm{N}\right)\end{array}$ & $\begin{array}{r}\text { Longitude } \\
\left({ }^{\circ} \mathrm{E}\right)\end{array}$ & $\begin{array}{r}\text { Lattice } \\
\text { water } \\
\text { (wt \%) }\end{array}$ & $\begin{array}{c}\text { Soil } \\
\text { organic C } \\
(\mathrm{wt} \%)\end{array}$ \\
\hline \multicolumn{5}{|c|}{ Continental USA } \\
\hline ARM-1 & 36.61 & 262.51 & 5.4 & 0.6 \\
\hline Austin Cary & 29.74 & 277.78 & 0.5 & 1.1 \\
\hline Beltsville & 39.03 & 283.15 & 0.4 & 0.8 \\
\hline Bondville & 40.01 & 271.71 & 3.8 & 1.6 \\
\hline Brookings & 44.35 & 263.16 & 2.9 & 2.0 \\
\hline Chestnut Ridge NOAA & 35.93 & 275.67 & 2.5 & 1.0 \\
\hline Coastal Sage UCI & 33.73 & 242.30 & 4.2 & 1.2 \\
\hline Coweeta & 35.07 & 276.56 & 4.5 & 1.7 \\
\hline Daniel Forest & 41.87 & 248.49 & 2.8 & 1.7 \\
\hline Desert Chaparral UCI & 33.61 & 243.55 & 1.6 & 0.2 \\
\hline Flag Ponderosa Pine & 35.44 & 248.20 & 4.1 & 1.3 \\
\hline Flag Wildfire & 35.45 & 248.23 & 4.4 & 2.0 \\
\hline Fort Peck & 48.31 & 254.90 & 3.4 & 1.2 \\
\hline Freeman Ranch & 29.95 & 262.00 & 5.3 & 2.0 \\
\hline GLEES & 41.36 & 253.76 & 5.0 & 4.9 \\
\hline Harvard Forest & 42.54 & 287.83 & 5.0 & 6.1 \\
\hline Houser-N & 34.58 & 248.14 & 2.4 & 0.6 \\
\hline Houser-S & 34.58 & 248.14 & 1.1 & 0.6 \\
\hline Howland & 45.20 & 291.26 & 3.9 & 8.1 \\
\hline Iowa Validation Site & 41.98 & 266.32 & 4.5 & 1.6 \\
\hline JERC & 31.24 & 275.54 & 1.0 & 0.7 \\
\hline Jonesboro & 35.75 & 269.24 & 2.3 & 0.8 \\
\hline Kendall & 31.74 & 250.06 & 3.8 & 0.8 \\
\hline Lucky Hills & 31.74 & 249.95 & 1.5 & 3.6 \\
\hline Manitou Forest & 39.10 & 254.90 & 2.8 & 0.5 \\
\hline McNeal & 31.60 & 250.30 & 6.8 & 1.0 \\
\hline Metolius & 44.45 & 238.44 & 4.6 & 1.4 \\
\hline Morgan Monroe & 39.32 & 273.59 & 3.2 & 1.2 \\
\hline Mozark & 38.74 & 267.80 & 3.6 & 1.4 \\
\hline Neb Field 3 & 41.16 & 263.53 & 3.7 & 1.3 \\
\hline OS-19-soil & 33.20 & 242.63 & 4.2 & 1.5 \\
\hline OS-beach & 33.19 & 242.62 & 0.7 & 0.1 \\
\hline P301 & 37.07 & 240.81 & 4.3 & 2.4 \\
\hline Park Falls & 45.95 & 269.73 & 1.8 & 1.4 \\
\hline Rancho No Tengo & 31.74 & 249.98 & 3.2 & 0.4 \\
\hline Reynolds Creek & 43.12 & 243.28 & 5.7 & 2.6 \\
\hline Rosemount & 44.71 & 266.91 & 2.9 & 1.7 \\
\hline San Pedro & 31.56 & 249.86 & 1.6 & 0.5 \\
\hline Santa Rita Creosote & 31.91 & 249.16 & 2.5 & 0.3 \\
\hline Savannah River & 33.38 & 278.43 & 0.8 & 0.5 \\
\hline Sevilleta New Grass & 34.40 & 253.33 & 0.8 & 0.6 \\
\hline Shale Hills & 40.66 & 282.09 & 4.7 & 1.3 \\
\hline SMAP-OK & 36.06 & 262.78 & 5.2 & 0.7 \\
\hline Soaproot & 37.03 & 240.74 & 4.5 & 3.3 \\
\hline Sterling & 38.97 & 282.51 & 6.4 & 0.5 \\
\hline Tenderfoot Creek & 46.95 & 249.11 & 4.0 & 1.1 \\
\hline Tonzi Ranch & 38.43 & 239.03 & 5.7 & 0.6 \\
\hline UMBS & 45.56 & 275.29 & 0.4 & 0.8 \\
\hline UVA & 37.92 & 281.73 & 2.6 & 1.2 \\
\hline Wind River & 45.82 & 238.05 & 6.4 & 3.8 \\
\hline Average & & & 3.4 & 1.6 \\
\hline Std dev & & & 1.7 & 1.5 \\
\hline
\end{tabular}


Table 2. Continued.

\begin{tabular}{|c|c|c|c|c|}
\hline Site & $\begin{array}{l}\text { Latitude } \\
\qquad\left({ }^{\circ} \mathrm{N}\right)\end{array}$ & $\begin{array}{r}\text { Longitude } \\
\left({ }^{\circ} \mathrm{E}\right)\end{array}$ & $\begin{array}{r}\text { Lattice } \\
\text { water } \\
(\mathrm{wt} \%)\end{array}$ & $\begin{array}{c}\text { Soil } \\
\text { organic C } \\
\text { (wt } \%)\end{array}$ \\
\hline \multicolumn{5}{|c|}{ Hawaii } \\
\hline Island Dairy & 20.00 & 204.71 & 20.9 & 3.3 \\
\hline Mana Road & 19.72 & 204.57 & 7.4 & 2.1 \\
\hline Silver Sword & 19.77 & 204.58 & 9.6 & 1.8 \\
\hline Average & & & 12.6 & 2.4 \\
\hline Std dev & & & 7.3 & 0.8 \\
\hline \multicolumn{5}{|c|}{ Outside of the US } \\
\hline KLEE & 0.28 & 36.87 & 6.0 & 1.1 \\
\hline Mpala North & 0.49 & 36.87 & 2.9 & 0.8 \\
\hline Pe-de-Gigante & -21.62 & 312.37 & 1.7 & 1.9 \\
\hline Rietholzbach & 47.38 & 8.99 & 5.1 & 3.1 \\
\hline Toulouse & 43.38 & 1.29 & 3.0 & 0.8 \\
\hline Average & & & 3.7 & 1.5 \\
\hline Std dev & & & 1.8 & 1.0 \\
\hline
\end{tabular}

masks the soil moisture signal, making soil moisture determination impossible. Whereas a known small amount of snow can be accounted for (Desilets et al., 2010), for example, using a correction factor similar to that for vegetation, we advise against calibrating soil moisture and determining soil moisture in the presence of snow because (1) the correction may be substantial and the signal due to soil moisture too weak to produce a well defined calibration function, (2) snow cover may be non-uniform, making the determination of footprint-average snow water equivalent inaccurate, and (3) snow cover may be variable in time, making it necessary to recompute corrections frequently, which requires snow data.

\subsection{Measurement volume}

\subsubsection{Measurement area (horizontal footprint)}

The horizontal footprint, which is defined as the area around the probe from which $86 \%\left(1-e^{-2}\right)$ of counted neutrons arise, is a circle with a diameter of $\sim 660 \mathrm{~m}$ at sea level (Zreda et al., 2008). It depends on the chemical and physical properties of the atmosphere, and is nearly independent of soil moisture content. This value, which was obtained from MCNPX modeling experiments, is consistent with knowledge of neutron transport in air (Glasstone and Edlund, 1952; Hess et al., 1959), and its order of magnitude has been confirmed by neutron measurements across water-land boundaries (own data, unpublished).

The horizontal footprint depends on atmospheric density and humidity. First, because the scattering mean free path for neutrons depends inversely on the number of molecules per unit volume of air, the footprint increases with decreasing air density and thus also with elevation. The increase of the footprint between sea level and $3000 \mathrm{~m}$ of altitude is approximately $25 \%$.

Second, the presence in the air of water vapor shortens the scattering mean free path for neutrons, and therefore the footprint decreases with increasing partial pressure of water vapor. MCNPX calculations show a reduction in the footprint radius of approximately $10 \%$ between dry air and saturated air $\left(22 \mathrm{~g} \mathrm{H}_{2} \mathrm{O}\right.$ in $1 \mathrm{~m}^{3}$ of air).

\subsubsection{Measurement depth}

The effective depth of measurement, which is defined as the thickness of soil from which $86 \%\left(1-e^{-2}\right)$ of counted neutrons arise, depends strongly on soil moisture (Zreda et al., 2008). It decreases non-linearly from $\sim 76 \mathrm{~cm}$ in dry soils (with zero water content) to $\sim 12 \mathrm{~cm}$ in saturated soils $\left(0.40 \mathrm{~m}^{3} \mathrm{~m}^{-3}\right)$ and is independent of air pressure (Zreda et al., 2008). This result, which was again obtained from MCNPX simulations, agrees with the understanding of transport of cosmic-ray neutrons in soil, and it is of the same order of magnitude as the radius of influence of a conventional neutron probe; however, it has not yet been verified using field experiments.

The measurement depth depends on the amount of lattice water in soil minerals (Sect. 2.3.1) and on the amount of water in soil organic matter (Sect. 2.3.2), in the same way in which it depends on soil moisture. Both sources of water vary significantly in space (Table 2). The effect of lattice water and organic matter on the measurement depth is through shortening the scattering mean free path within soils due to additional hydrogen. Hydrogen atoms in pore water in lattice water and in organic matter have the same effect on scattering of neutrons. Hence, higher lattice water and organic matter result in shallower measurement depth.

\subsection{Calibration}

The cosmic-ray probe measures cosmic-ray neutron intensity not soil moisture, and the measured intensity must then be converted to soil moisture using a calibration function, such as that in Eq. (4) and Fig. 6 (black line). Fortunately, this calibration function (Eq. 4), developed from nuclear physics theory (Desilets et al., 2010), is simple, monotonic, nearly invariant with soil chemistry (except lattice water) and texture, and requires only one free parameter to be fitted. Thus, a single representative measurement of average soil moisture content in the footprint is sufficient for calibration (although measuring area-average soil moisture does involve collecting numerous soil samples within the footprint and measuring their soil moisture gravimetrically by oven-drying; see Sect. 2.5.3). Measured neutron intensity is then compared with the average soil moisture, and the calibration parameter $\phi_{0}$ in Eq. (4) is calculated.

The presence of lattice water or organic matter in soil minerals increases the stopping power of the soil leading to a 


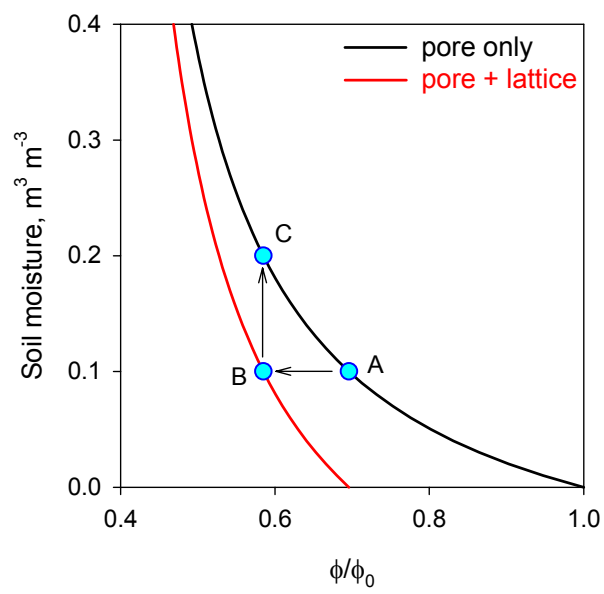

Fig. 6. Calibration function derived from MCNPX modeling for soil with no lattice water (black) and with the equivalent of $0.1 \mathrm{~m}^{3} \mathrm{~m}^{-3}$ lattice water (red). A, B and C are hypothetical calibration points when lattice water is neglected (A), when it is included (B) and when it is included and plotted on the original calibration line (C).

decrease in the neutron intensity (Fig. 6, red line). Two different effects of this additional water must be considered: the larger effect is the decrease in the count rate of neutrons (shift from black line to red); the smaller effect is the change in the slope of the calibration function (difference between the slope at point $\mathrm{A}$ and that at point $\mathrm{C}$ ). The black line in Fig. 6 is the standard calibration function (Eq. 4) and the red line is the calibration function when lattice water and water in organic matter are added to pore water. The new function is produced by shifting the standard function down by the amount of additional water. Calibration can be performed on the total pore water plus lattice and organic matter water, and soil moisture is then computed by subtracting lattice and organic matter water from the measured neutron-derived moisture. This approach was used with the conventional neutron probe (Gardner and Kirkham, 1952).

\subsubsection{Calibration options}

Our research suggests the following options for calibrating the cosmic-ray soil moisture probe. The first uses the areaaverage soil moisture obtained from a large number of samples collected within the footprint at the same time. Most factors discussed above are implicitly included in this type of calibration. When soil moisture samples are not available, but soil samples are available for chemical analysis, soil chemistry, particularly lattice water content, and the site location can be used to construct a local calibration function. When no local samples are available, the universal function (Franz et al., 2012b) can be used.

The first method is preferred, and all COSMOS probes are calibrated on area-average soil moisture. The field calibration on average soil moisture derived from multiple samples will be described in detail elsewhere. Below we give only a brief summary.

\subsubsection{Field calibration}

Soil samples are collected around the probe, soil moisture is measured using the oven-drying method (Gardner, 1986), and area-average soil moisture is computed. Arguments have been made regarding the distribution of samples within the cosmic-ray probe footprint or regarding the weighting of the samples, but we found that these have almost no bearing on the calculated average soil moisture. Having a large number of samples is critical, and for the COSMOS project we settled on the standard of 108 samples distributed as follows: (1) three radial distances from the probe: $25 \mathrm{~m}, 75 \mathrm{~m}$, and $175 \mathrm{~m}$, plus or minus a few meters, computed to give all samples the same weight so that a simple arithmetic average could be used; (2) six radial directions, every $60^{\circ}$ in the horizontal starting from an arbitrary azimuth; thus, each radial distance will be sampled six times to provide a representative average; and (3) six depths, from $0 \mathrm{~cm}$ to $30 \mathrm{~cm}$ in $5 \mathrm{~cm}$ increments to capture the profiles of soil moisture. With 108 samples the computed area-average soil moisture values are determined to the accuracy of better than $0.01 \mathrm{~m}^{3} \mathrm{~m}^{-3}$. Weighting for distance or for depth produces only small changes to the average soil moisture and is typically not worth undertaking unless sharp wetting fronts are present due to a recent rain event or significant layering in the top $30 \mathrm{~cm}$ (Franz et al., 2012a).

Undisturbed soil samples are collected using a split corer of $30.48 \mathrm{~cm}$ ( 1 foot) length and $5.08 \mathrm{~cm}$ (2 inches) inner diameter with stainless steel liners $5.02 \mathrm{~cm}$ in length and $4.8 \mathrm{~cm}$ inner diameter. The corer is driven into the soil, dug out gently to preserve undisturbed soil inside the liners, opened and sectioned. The soil samples are transferred to soil tins and sealed using electrical tape to prevent moisture loss. If the liner is full, the soil sample is said to have known volume, and it yields gravimetric moisture content and bulk density from which volumetric moisture content is computed. Otherwise, only gravimetric moisture contents can be determined, and in order to compute volumetric water content the bulk density must be assigned, for example that from the volumetric samples in the calibration data set. Sometimes, in wet and soft soils, there is significant (up to $20 \%$ in our experience) compression inside the corer, and the data have to be uncompressed to give correct values of bulk density and volumetric water content.

The computed moisture values are combined to give the area-average soil moisture that is used with Eq. (4) to obtain the calibration parameter $\phi_{0}$. The calibration data sets, parameters and derived values of $\phi_{0}$ for all COSMOS probes are available at http://cosmos.hwr.arizona.edu. Empirical equations rather than the theoretical Eq. (4) can be used as calibration functions (Rivera Villareyes et al., 2011; 
Franz et al., 2012c), for example to account for sources of hydrogen other than soil moisture.

\subsubsection{Temporal stability of calibration}

The COSMOS probe at the San Pedro site has been used continuously since its installation in July 2007 and provides the longest record of fast neutron intensity. The probe has required no service except one battery change after four years of continuous operation. Soil moisture computed from the measured fast neutron intensity, $\phi$, using Eq. (4), calibrated on soil samples collected on 5 July 2007, ranges from less than $0.02 \mathrm{~m}^{3} \mathrm{~m}^{-3}$ during summer dry periods to $0.37 \mathrm{~m}^{3} \mathrm{~m}^{-3}$ during the monsoon of August 2008 (Fig. 7). We obtained nine sets of soil samples at different times to check the neutron-derived soil moisture (Fig. 7). All nine instantaneous soil moisture values determined using the oven-drying method on numerous field samples collected within the cosmic-ray footprint agree well with those derived from neutron data. The average of absolute differences is $0.013 \mathrm{~m}^{3} \mathrm{~m}^{-3}$, and there is no trend in absolute differences with time or with the magnitude of soil moisture. This result demonstrates the cosmic-ray probe's long-term stability; the probe calibrated at one time and at any moisture content gives correct soil moisture contents at other times over a period of $4.5 \mathrm{yr}$. Based on this result, longer-term stability can reasonably be expected at this site. Similar assessments at other sites should be made to make a more general conclusion about the stability of the cosmic-ray probe and of local calibrations.

\subsection{Uncertainties}

The measured neutron count, $C$, which is a proxy for intensity $\phi$, obeys Poisson statistics (Knoll, 2000) in which the variance is equal to $C$, the standard deviation is $C^{0.5}$ and the coefficient of variation is $C^{-0.5}$. Thus, measurement precision increases with the number of counts, which at a given location is proportional to the counting interval and inversely proportional to the soil moisture content (see Fig. 6). Because $C$ increases with altitude and geomagnetic latitude (Sect. 2.1), precision increases accordingly. COSMOS probes have typical count rates between about 400 counts per hour (cph) at sea level, low latitude and over wet soils (e.g., the Island Dairy site in Hawaii, http://cosmos.hwr.arizona. edu, Level 1 data), and $\sim 6000 \mathrm{cph}$ at an altitude of $3000 \mathrm{~m}$, mid latitude and over dry soil (e.g., the Manitou site in Colorado), which corresponds to counting uncertainties of $5 \%$ $\left(400^{-0.5}\right)$ and $1.3 \%\left(6000^{-0.5}\right)$, respectively. Quadrupling the counting time will halve $\left(4^{-0.5}\right)$ these uncertainties. The precision of soil moisture determination can then be computed by propagating this counting uncertainty through the calibration function (Eq. 4).

The accuracy of soil moisture determination depends also on the quality of the local calibration, which depends on

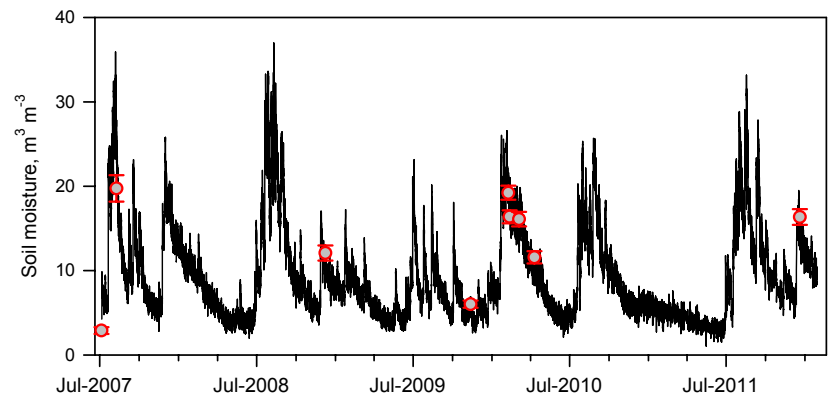

Fig. 7. Soil moisture from cosmic-ray neutron measurements (line) compared to that from gravimetric measurements on samples collected within the cosmic-ray footprint (symbols), San Pedro River valley, Arizona. The neutron data are corrected for temporal variations in the incoming neutron intensity, atmospheric pressure and atmospheric water vapor. The gravimetric measurements are averages of between 27 and 108 soil samples. The mean of nine absolute differences between the two is $0.013 \mathrm{~m}^{3} \mathrm{~m}^{-3}$.

uncertainty in the independent determination of soil moisture and the uncertainty in the neutron count at the time of calibration. Thus, many soil samples and a long neutron counting time are needed to reduce calibration uncertainties. However, typically a hundred soil moisture samples give a standard error of the mean soil moisture of less than $0.01 \mathrm{~m}^{3} \mathrm{~m}^{-3}$ and counting for just a few hours reduces the standard deviation in neutron count to less than $2 \%$ at most locations. The accuracy may be affected by other factors, such as strong vertical soil moisture gradients that can develop following precipitation and infiltration. Our modeling suggests that in the worst case of a sharp infiltration front (piston flow), the bias is smaller than $0.03 \mathrm{~m}^{3} \mathrm{~m}^{-3}$ (Franz et al., 2012a). In reality, piston flow is unlikely at the scale of the COSMOS footprint and in the case of a diffused front the bias due to infiltration decreases to ca. $0.01 \mathrm{~m}^{3} \mathrm{~m}^{-3}$, and even that condition is short lived, and disappears within a day or so after precipitation (Hillel, 1998).

\subsection{Potential limitations}

Like all methods, the cosmic-ray method has potential limitations. As discussed in Sects. 2.4.1. and 2.5.1, one possible problem is the presence in the footprint of hydrogen other than that in soil water, for example in hydrous minerals (clay minerals, hornblende, gypsum, etc) or in vegetation and soil organic matter. If this hydrogen content is constant in time, its effect will be allowed for in the local calibration and become largely irrelevant. However, if it varies in time, such as it might in seasonal vegetation, it becomes an additional unknown and soil moisture can be distinguished only if changes in the additional hydrogen content can be quantified independently. However, neutron modeling studies and our own limited field measurements suggest that, because the amount of hydrogen in many types of vegetation is small (on the order of $\mathrm{mm}$ of water equivalent) compared to that in soil 
water and because only part of this hydrogen changes in time (for example seasonally), the effect of vegetation changes on the neutron-derived soil moisture is small, and it is implicitly embedded in local calibration. However, conceivably in some vegetation types such as fast growing crops, fluctuations in hydrogen levels within vegetation (including roots) could be large enough to affect the determination of soil moisture by several percent (Hornbuckle et al., 2011). A theoretical account of vegetation has been developed (Franz et al., 2012b), but more field measurements over different vegetation types are needed to assess quantitatively the effect of vegetation on cosmic-ray neutrons.

The same neutron intensity can be produced above surfaces with spatially (horizontally and vertically) variable soil moisture content. Soil moisture heterogeneity results in variable neutron emissions from different parts of the soil and these neutrons, when mixed in the air above the surface, will have a density that is the weighted average of the individual emissions. It is conceivable that two or more different soil moisture fields with different spatial patterns and area-average soil moisture could result in the same measured neutron density, and this density would be interpreted as corresponding to just one computed area-average soil moisture over the COSMOS probe footprint. Preliminary neutron simulations and measurements suggest that possible nonuniqueness associated with soil moisture pattern usually does not lead to large errors in the computed soil moisture, but rigorous studies are still needed to quantify this uncertainty.

Water at the surface, such as snow on the ground, runoff, or intercepted precipitation, can depress the fast neutron signal, leading to (sometimes significantly) overestimated, soil moisture (for example, the Rietholzbach site, Switzerland). It may be possible to detect and quantify above-surface water, for example snow (Rasmussen et al., 2012; Zreda et al., 2011; also Sect. 3.4.2) or vegetation (Sect. 3.4.2), but this requires additional research.

\section{The COsmic-ray Soil Moisture Observing System (the COSMOS)}

The COsmic-ray Soil Moisture Observing System, funded by the US National Science Foundation in 2009, comprises 48 cosmic-ray soil moisture probes installed at sites throughout the USA and five abroad (Fig. 8), and will eventually grow to 500 probes. (The network also includes six affiliated probes installed and operated by others, but displayed on the COSMOS web site.) Each COSMOS probe has two neutron detectors to measure both fast neutrons and thermal neutrons. The fast (measured with the moderated detector) neutron data are used for measuring soil moisture while the thermal (from the unmoderated detector) neutron data are used for detecting and potentially quantifying water that is present above the land surface in snow, vegetation, etc. The cosmic-ray probes have been designed to be rugged, energy-efficient and independently powered using photovoltaic cells, and they are equipped with an Iridium satellite modem. Thus, they are independent and can be installed anywhere with sufficient sky view for solar panels and Iridium reception. As previously mentioned, in addition to the network of cosmic-ray probes, the COSMOS also includes two (for redundancy) neutron monitors to measure the variation in time of the intensity of incoming high-energy secondary neutrons which are the precursors to fast neutrons. The system also includes computers and software for data acquisition, processing and modeling, and for disseminating data, results and information via the internet (see http://cosmos.hwr.arizona.edu).

\subsection{Design of the COSMOS probe}

The cosmic-ray soil moisture probe (Fig. 9), comprising neutron detectors plus associated electronics, is manufactured by Hydroinnova, LLC of Albuquerque, New Mexico, USA (www.hydroinnova.com). It consists of two neutron detectors: a bare detector that responds mainly to thermal neutrons and a polyethylene-shielded detector that responds mainly to epithermal-fast neutrons. Each counter has its own highvoltage power supply and a pulse module to analyze the signal generated by the neutron detector tube. An Iridium satellite modem then transmits the data at user-defined time intervals. Power is supplied by a rechargeable battery connected to a solar panel and controller.

Gas-filled detectors comprise a metal tube filled with a gas that reacts with thermal neutrons that enter the tube (Krane, 1988; Knoll, 2000). The sensitive gas is enriched in ${ }^{3} \mathrm{He}$ or ${ }^{10} \mathrm{~B}$, both of which have a high neutron-absorption crosssection. A neutron absorption reaction results in the emission of charged particles, creating ionization in the tube, which results in an electronic pulse that can be read by chargesensitive electronics. A potential of $\sim 1 \mathrm{kV}$ is applied between the tube wall (the cathode) and a thin central wire (the anode). When a thermal neutron collides with an atom of the enriched gas, the resulting ionization produces a cascade of electrons, called a Townsend avalanche. These electrons are attracted to the anode and produce a charge pulse. This pulse is amplified, shaped and passed through a filter by sensitive hybrid analog/digital electronics coupled directly to the detector. The number of counts over a set time is sent from the pulse module to the data logger where it is recorded. In the probe the high voltage required by the proportional counters is produced by the power supply housed in the pulse module, with power for the instrument taken from a $12 \mathrm{~V} \mathrm{DC}$ source, usually a rechargeable battery connected to a solar panel. The Iridium satellite modem is inside the data logger and connects via a coaxial cable to an external antenna. The probe's data logger also houses temperature, humidity and pressure sensors which are used for instrumental diagnostics and corrections (pressure is equilibrated to that outside the box; temperature and relative humidity represent the internal conditions that could affect the electronics). Data are 

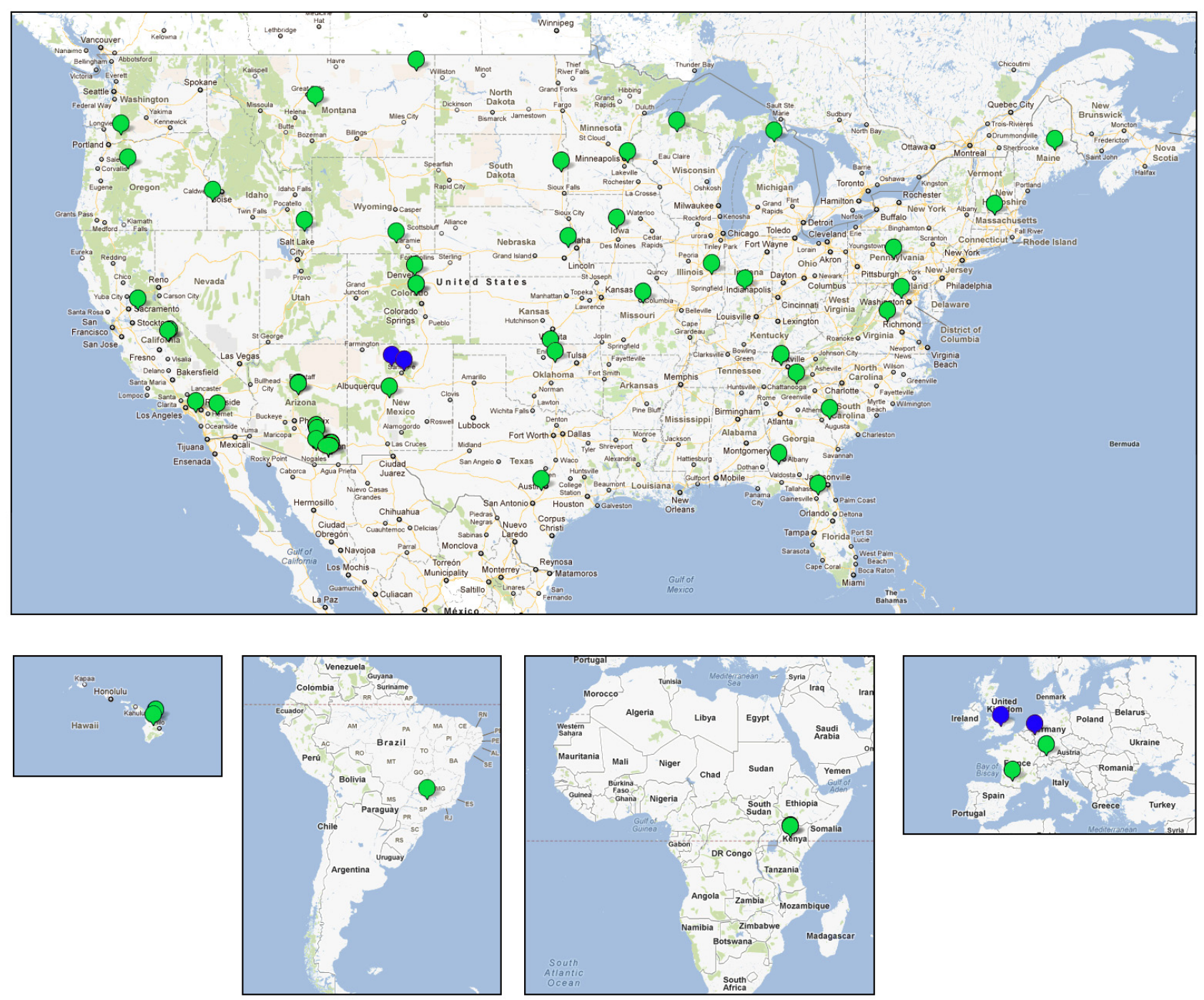

Fig. 8. Fifty-three COSMOS probes (green) and five COSMOS-affiliated probes (blue) installed before March 2012; ten additional probes are planned for deployment in 2012. Up-to-date information on the sites is available at http://cosmos.hwr.arizona.edu.

stored in the data logger on redundant secure digital (SD) cards and telemetered via the Iridium modem to a data acquisition computer.

\subsection{Design of the COSMOS network}

The first 53 COSMOS probes (Fig. 8) were preferentially installed at sites where other meteorological and hydrological measurements are being made. These COSMOS and ancillary data are used in research that centers primarily on understanding the probe response to varying moisture amounts and also on understanding land-surface and ecohydrological processes, developing data assimilation techniques, calibrating and/or validating satellite microwave sensors, and evaluating the soil moisture from weather and seasonal prediction.

The COSMOS array (Fig. 10) comprises neutron monitors that provide the information on the temporal variations in the incoming cosmic-ray neutron intensity and also computer clusters that are used for data acquisition, modeling and computations, and data dissemination. Individual COSMOS probes send the neutron data and ancillary data (pressure, temperature, relative humidity, voltage) to a server where soil moisture is computed and posted immediately on the COSMOS web site.

\subsection{Data acquisition, processing and dissemination}

Data are acquired at one-hour intervals and sent via Iridium satellite to the COSMOS server where they are processed and placed in the public domain. These collected data include thermal neutron count rate, fast neutron count rate, barometric pressure, relative humidity, and temperature. The neutron count rates are cumulative over the prescribed time interval 

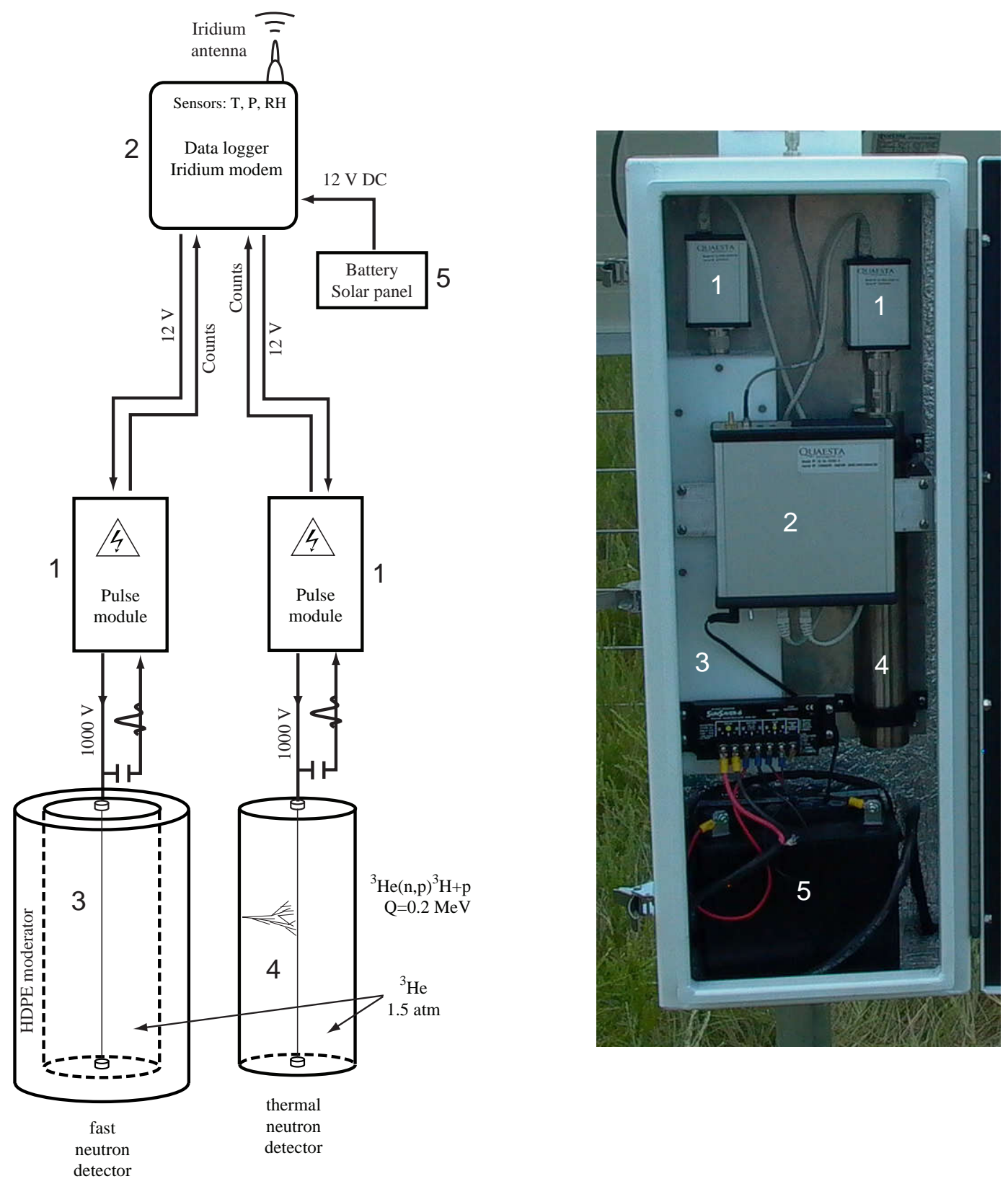

Fig. 9. A cosmic-ray probe consists of neutron detectors connected to electronic pulse modules, data logger, satellite modem, and solar panel and rechargeable battery. Please also see the manufacturer's web page for additional information about the cosmic-ray probe: http: //hydroinnova.com/ps_soil.html\#stationary.

while other measurements are taken at the end of the time interval.

\subsubsection{Data reduction, quality control}

To reduce bandwidth over the Iridium satellite network, the hourly data are sent by e-mail as compressed (10 bytes) binary attachments. When these emails are downloaded from the server, the attachments are uncompressed and formatted as ASCII text with a data resolution of 1 count for neutrons,
$0.1 \mathrm{mb}$ for pressure, $1 \%$ for relative humidity and $1{ }^{\circ} \mathrm{C}$ for temperature.

The pressure, relative humidity and temperature sensors that are located inside the probe's housing are used as diagnostic tools for the probe's electronics. The probe also emails power supply voltage ( $0.1 \mathrm{~V}$ resolution) every hour to monitor solar panel efficiency and a neutron pulse height spectrum (in 128 bins) every 2 days to allow monitoring of the neutron detectors' stability. 


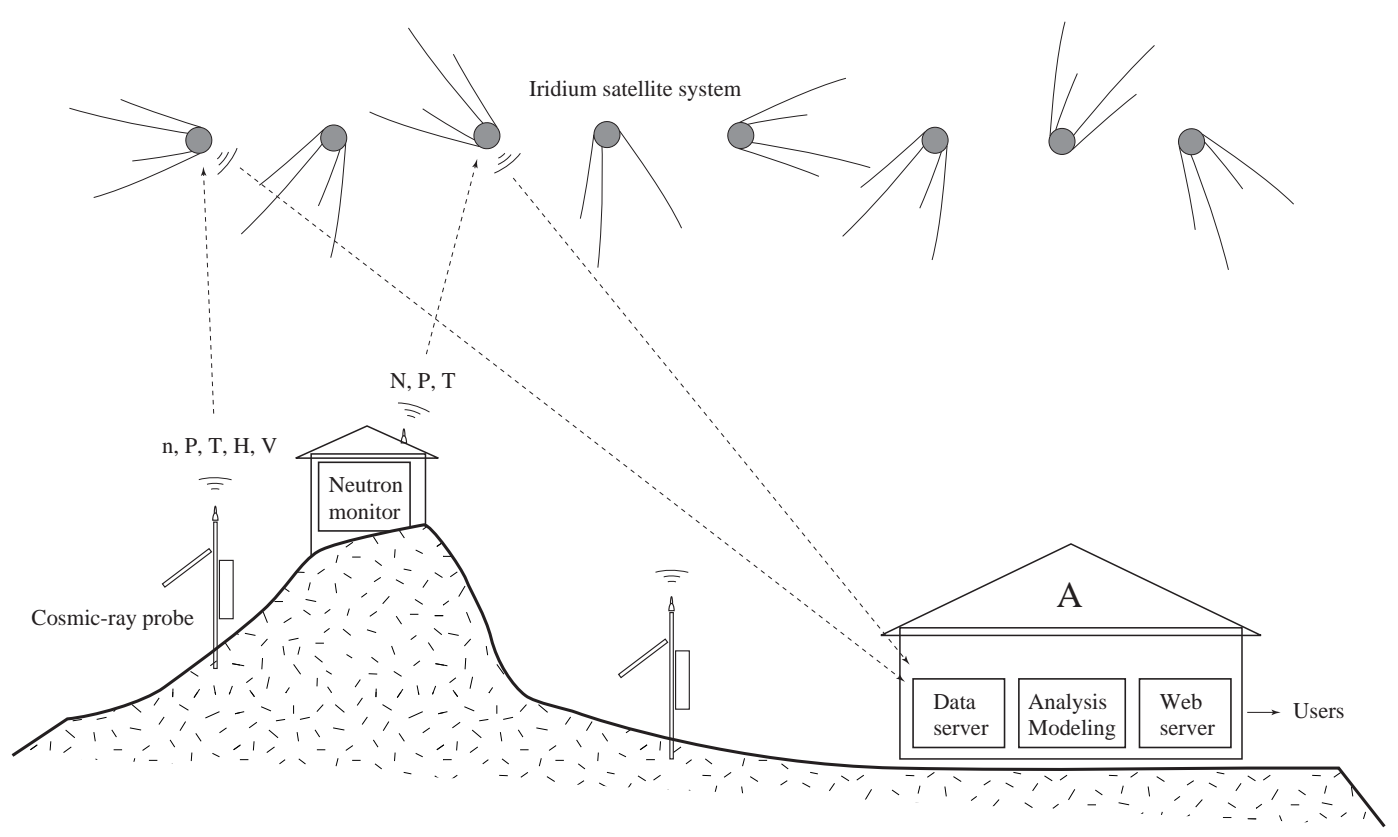

Fig. 10. The COSMOS consists of cosmic-ray probes that measure fast and thermal neutrons; neutron monitors that measure high-energy neutrons; a data transmission system (using Iridium satellite constellation); and computers for data acquisition and processing, analysis and modeling, and data and information dissemination. Key to abbreviations: $n=$ fast neutron count rate; $P=$ atmospheric pressure; $T=$ air temperature; $H=$ relative humidity; $V=$ battery voltage; $N=$ high-energy neutron count rate; A stands for Arizona where the COSMOS servers are located.

Quality control procedures are applied to raw cosmic-ray probe data before computing soil moisture. Data are flagged when (a) counting data are not of one-hour duration, (b) neutron count differs from the previous value by more than $20 \%$, (c) the relative humidity is greater than $80 \%$ inside the probe box (inside which there is a desiccant to keep it dry), and (d) the battery voltage is less than $11.8 \mathrm{~V}$. It is possible that with these (arbitrary) cutoffs good data can be removed and bad data allowed by mistake. Therefore, these cutoff values may have to be changed on the basis of experience.

\subsubsection{Computations, corrections}

Quality-controlled probe data are then corrected to account for temporal changes in pressure, atmospheric water vapor and incoming neutron flux, and then rescaled to match the location and configuration of the original cosmic-ray soil moisture probe located at the COSMOS station in the San Pedro River basin in Arizona (Zreda et al., 2008). The pressure correction factor $f_{P}$ is given by

$f_{P}=\exp \left(\frac{P_{0}-P}{L}\right)$,

where $L$ is the mass attenuation length for high-energy neutrons (mbar or equivalent in $\mathrm{g} \mathrm{cm}^{-2}$ ) that varies progressively between $\sim 128 \mathrm{~g} \mathrm{~cm}^{-2}$ at high latitudes and $142 \mathrm{~g} \mathrm{~cm}^{-2}$ at the equator (Desilets and Zreda, 2003), $P$ is the pressure at the specific site, and $P_{0}$ is an arbitrary reference pressure (which can be selected to be the long-term average pressure at the specific site, sea-level pressure, or long-term average pressure at a different reference site). The corrected count rate equals the raw count rate multiplied by $f_{P}$; thus, the corrected count rate is what the probe would measure if it were counting neutrons at reference pressure with everything else kept unchanged.

The correction factor for atmospheric water vapor, $f_{\mathrm{wv}}$, is of the form

$f_{\mathrm{wv}}=1+0.0054 \cdot \Delta \rho_{v 0}$,

where $\Delta \rho_{v 0}=\rho_{v 0}-\rho_{v 0}^{\mathrm{ref}}$ is the difference in the absolute humidity at the time of measurement $\left(\rho_{v 0}\right)$ and at the reference time $\left(\rho_{v 0}^{\mathrm{ref}}\right)$, for example that at the time of calibration, all measured at the surface in $\mathrm{g} \mathrm{m}^{-3}$. Details of the water vapor correction will be published elsewhere.

Temporal changes in incoming neutron flux (Fig. 4) are measured using cosmic-ray neutron monitors which are designed to detect high-energy secondary neutrons while being insensitive to low-energy neutrons (Simpson, 2000). Removal of secular variations, for example due to the sunspot cycle or diurnal fluctuations (e.g., Moraal et al., 2005), is straightforward. The required correction factor, $f_{i}$, is merely the ratio of the measured neutron monitor intensity, $I_{m}$, at a given time to a specified baseline reference intensity, $I_{0}$, and can be expressed as

$f_{i}=\frac{I_{m}}{I_{0}}$. 
Currently, the neutron monitor at Jungfraujoch, Switzerland, is being used, but the COSMOS project has two dedicated neutron monitors to be deployed in 2012. The reference intensity is that at Jungfraujoch on 1 May 2011. The corrected fast neutron intensity is obtained by dividing the measured fast neutron intensity from the COSMOS probe by $f_{i}$; the corrected value is what the probe would measure if it were counting neutrons at Jungfraujoch on 1 May 2011, with everything else kept unchanged.

The three corrections described above and their combination are shown in Fig. 11. Pressure variations have the largest effect on the neutron intensity, with the correction factor ranging from 0.9 to 1.1 and a small seasonal effect. Water vapor correction displays larger seasonality, but a smaller range from 0.99 to 1.07 . The intensity correction ranges from 0.95 to 1.05 and has no seasonal trend. Due to cancelling effect, the combined correction has a smaller magnitude than the pressure correction, and ranges from 0.95 to 1.08 .

After the corrections for temporal effects have been made, neutron count rates are rescaled to correspond to the location of the original COSMOS probe site in the San Pedro River basin, Arizona. Long-term average pressure and geomagnetic cutoff rigidity (Smart and Shea, 2001) at each site are used to compute the incoming cosmic-ray secondary neutron intensity, this being a function of the location within the Earth's atmosphere and geomagnetic field (Desilets and Zreda, 2003).

Lattice water is measured on soil samples and added to the measured soil moisture to produce a calibration function on total (pore plus lattice) water. When soil moisture is determined from measured neutron data, the lattice water is subtracted from the neutron-derived total water.

\subsubsection{Dissemination}

The COSMOS web site allows public access to the probe data at each stage: the raw (Level 1) hourly count data, the corrected (Level 2) hourly data, and the computed average soil moisture and measurement depth (Level 3) hourly and 12-h average data. Soil moisture profiles will be available in the future as Level 4 data. Appendix A describes data levels in more detail.

\subsection{Examples of COSMOS data}

Time series of soil moisture from the San Pedro (Lewis Springs) and Mount Lemmon sites and of snow water equivalent from Mount Lemmon have been reported elsewhere (Zreda et al., 2008; Desilets et al., 2010). Here we show recent data from three COSMOS sites: the Santa Rita site in Arizona (the cosmic-ray data are compared with those from a network of 180 time-domain transmissivity, TDT, probes), the Manitou site in Colorado (the data reveal changes in soil moisture and snow), and the Island Dairy and Silver Sword
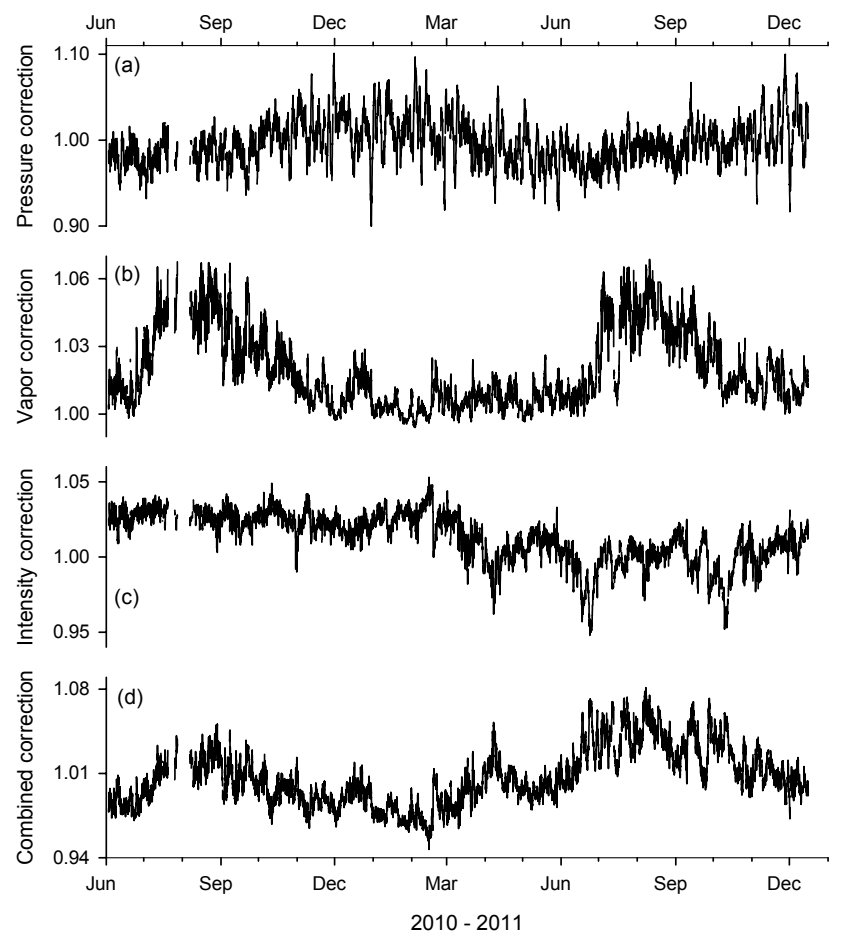

Fig. 11. COSMOS data from the Santa Rita site, near Tucson, Arizona, USA. Fast neutron intensity (a) was corrected for temporal changes in the incoming neutron intensity, atmospheric pressure and atmospheric water vapor. The rainfall intensity (b) is the average of 12 rain gauges distributed within $200 \mathrm{~m}$ of the COSMOS probe. Neutron-derived soil moisture (c, d) are computed using Eq. (4) with neutron intensity normalized using Eq. (A1), and is smoothed using a 12-h running average filter. Five separate soil moisture data sets (red squares), each based on multiple soil samples collected within the COSMOS footprint and measured gravimetrically following oven drying, are shown for comparison with the neutronderived data.

sites in Hawaii (the data reveal temporal trends in soil moisture under tropical humid and tropical dry climatic regimes).

\subsubsection{Santa Rita Experimental Range, Arizona}

A COSMOS probe was installed at the Santa Rita Experimental Range, south of Tucson, Arizona, in June 2010. The Santa Rita site is a creosote and mesquite shrubland at an elevation of ca. $990 \mathrm{~m}$. It is under semiarid climate, with average annual precipitation of ca. $250 \mathrm{~mm}$, falling mainly with summer monsoon rains and winter frontal rains. The area has a gentle slope and is dissected by small arroyos. The soils are mainly sandy loams with abundant stones, little organic matter and low lattice water.

The time series of fast neutron derived soil moisture and precipitation are shown in Fig. 12. The precipitation record is combined from multiple rain gauges installed within the COSMOS footprint. The measured neutron intensities were corrected for the temporal variations in the atmospheric 

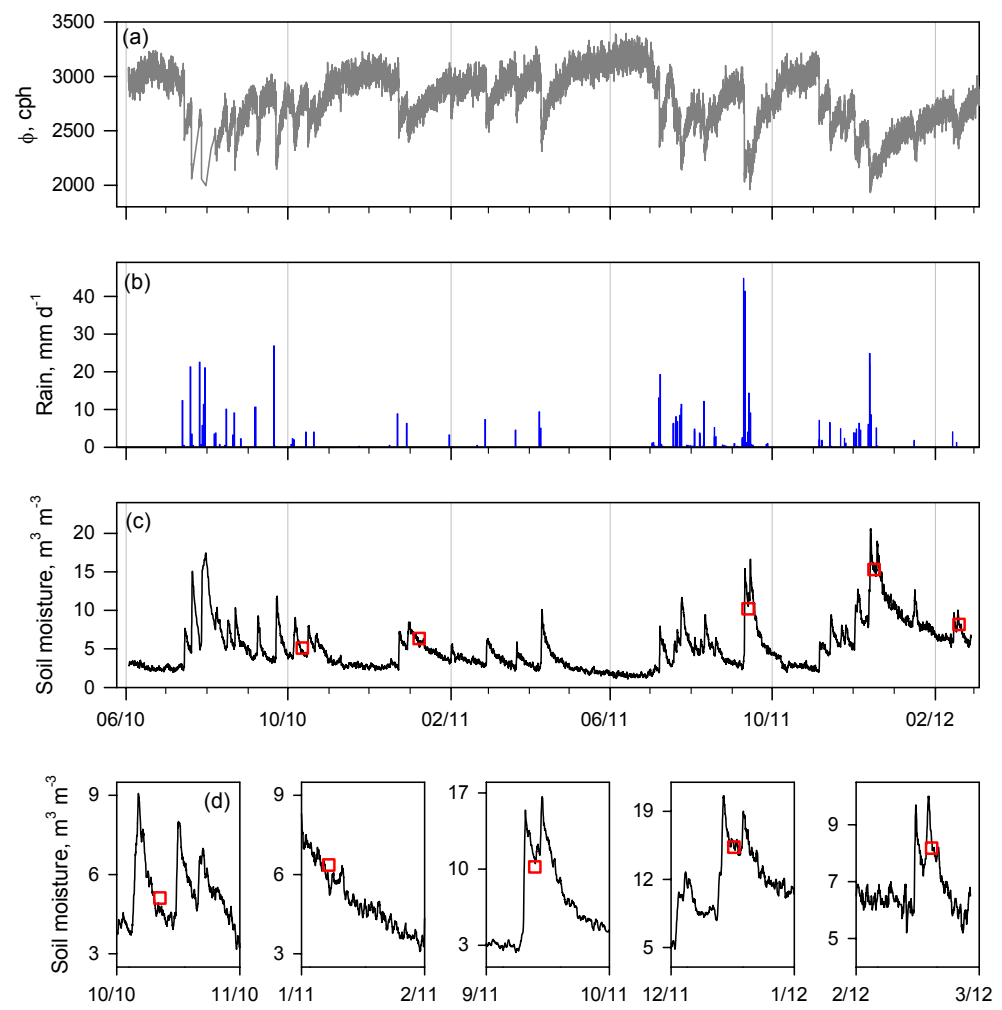

Fig. 12. Corrections for variations in pressure (a), atmospheric water vapor (b), the incident cosmic-ray neutron intensity (c), and the combined correction (d) computed for the Santa Rita COSMOS site in Arizona.

pressure (Eq. 5), incoming neutron intensity (Eq. 6), and atmospheric water vapor. There was no need to account for the vegetation because of its low density at the site.

Soil moisture shows four distinct seasons: two wet seasons, summer and winter, are separated by two dry seasons. The wet soil in the summer is due to the monsoon rains that are characterized by high intensity and short duration. The high summer temperatures lead to fast decrease in soil moisture due to evaporation. The winter soil wetness is due to frontal precipitation. Soil moisture remains high for a longer time because of low winter-time evaporation rates.

The COSMOS probe was calibrated using independent determination of area-average soil moisture from 108 soil samples collected within the cosmic-ray probe footprint in January 2011. Soil samples for calibration experiments were collected at four other times. Average soil moisture values for the five sample sets agree well with soil moisture derived from neutron measurements (Fig. 12), with the average absolute deviation approximately $0.01 \mathrm{~m}^{3} \mathrm{~m}^{-3}$. The five soil sample sets were used (Franz et al., 2012c) to construct a purely empirical calibration function, and that function agrees very well with the theoretically derived calibration equation of Desilets et al. (2010).

\subsubsection{Manitou Experimental Forest, Colorado}

Two COSMOS probes were installed in a pine forest near Woodland Park, Colorado, in October 2009. One probe is $\sim 1 \mathrm{~m}$ above the land surface while the other is on a tower above canopy $\sim 20 \mathrm{~m}$ above the surface. Neutron intensities below and above canopy can be used to investigate possible effects of forest and of canopy water on neutron signal. We describe neutron data and perform only preliminary analysis to show what can be inferred from neutron measurements. Details will be presented in future papers dedicated to specific topics.

Temporal changes of neutrons (Fig. 13a and b) reflect both soil moisture and snow (on the ground and on canopy). Because soil moisture and snow have not been separated, the collective signal ("soil moisture") is shown in Fig. 13c. Computation of "soil moisture" is based on fast neutron intensity from the probe on the ground (Fig. 13a) coupled with the local calibration function based on average soil moisture from 72 soil samples collected within the footprint in July 2010. The values of "soil moisture" are true soil moisture for summer months, but represent soil moisture plus any snow present.

When soil moisture is the main source of hydrogen that modifies neutron intensity, fast neutron count rate is usually much higher than that of thermal neutrons, and both fast and 

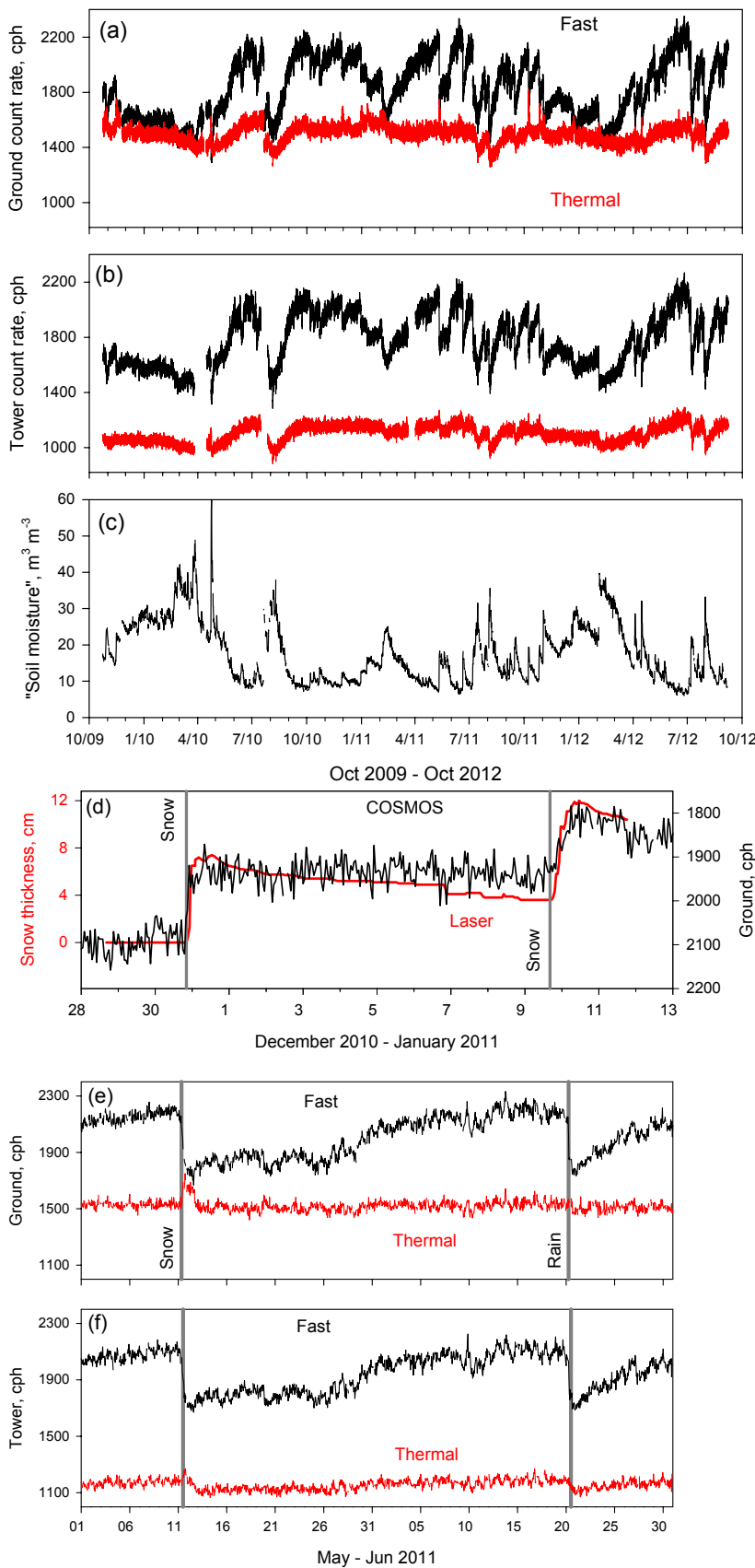

Fig. 13. Neutron intensity ( $\mathrm{cph}=$ counts per hour) from the probe on the ground (a) and on the tower (b), and computed "soil moisture" at the Manitou COSMOS site (c). "Soil moisture" includes any snow that might have been present on the ground or on canopy. Snow signal in cosmic-ray neutron intensity and snow thickness measured with a laser snow sensor (d), courtesy of Dave Gochis, NCAR. Response of fast and thermal neutrons to snow and rain events on the ground and above canopy (e, f).

thermal neutrons in both ground and tower probes decrease with increasing soil moisture (Fig. 13a and b). Fast neutrons have a greater sensitivity to soil moisture changes that thermal neutrons do; that is why the time series of fast neutrons is more jagged.

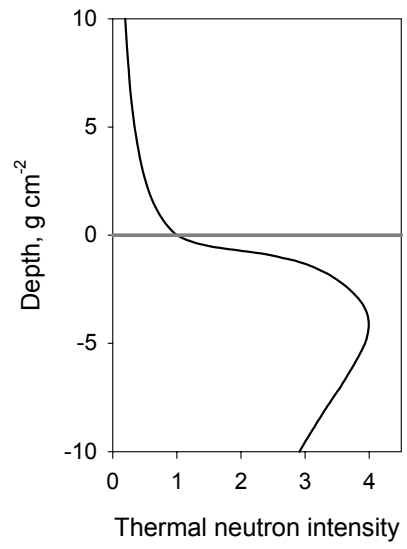

Fig. 14. Thermal neutron intensity near the air-water boundary calculated using the MCNPX code; the values are normalized to that at the surface.

When snow is present, the neutron responses are more complicated. First, as expected, fast neutron intensity from the probe on the ground decreases with increasing thickness of snow on the ground, as measured with a laser snow sensor (Fig. 13d). This suggests that neutron intensities are a quantitative measure of snow water equivalent, and that the neutron probe can be calibrated for snow. Similar conclusions have been reached by others (Desilets et al., 2010; Rasmussen et al., 2012). However, what snow is actually measured by that neutron probe? That on the ground, on the canopy or both? Data from the ground and tower probes taken together will answer these questions.

On the ground, fast neutrons decrease, while thermal neutrons increase (Fig. 13e). Above canopy, fast neutrons decrease, while thermal neutrons show almost no response (Fig. 13f). This suggests the presence of a hydrogen-rich shielding material between the two probes at the time of the increase. Thermal neutrons show a strong gradient at the air-water boundary (Fig. 14), with intensities increasing fast just below the water surface. Snow on canopy fits this pattern. It can be viewed as a layer of water (albeit with gaps between trees). Its effect is the same as if the probe were buried in snow, thus leading to an increase in thermal neutrons on the ground. The tower probe, which is above canopy snow, does not see the increase in thermal neutron intensity. This interpretation is supported by the examination of the response of the same two probes to snow and rain events (Fig. 13e and f). Fast neutron intensities in both probes decrease, as in the case of snow, but there is no increase in thermal neutrons in the probe on the ground because rain does not stay on canopy for long. Can snow on the ground be differentiated from that on canopy? Also, can either of them be separated from soil moisture? Answers to these questions will require further work.

If snow on canopy can be seen so clearly in the thermal neutron data, what about the forest? Trees contain 
approximately $50 \%$ of water. This water should increase the thermal neutron intensity on the ground (below the bulk of biomass), but not that above canopy. This is indeed the case; the intensity of thermal neutrons on the ground is approximately $35 \%$ higher than that above the canopy (Fig. 13a and $b$ ). This difference persists through the entire record, with some short-term deviations due to snow on canopy, and with annual fluctuations possibly due to seasonally variable amount of water in trees. The ratio of ground-to-tower thermal neutron intensities should depend on the amount of biomass. With proper calibration, thermal neutrons measured with probes on the ground and above canopy can be used to quantify the biomass between the two probes.

\subsubsection{Silver Sword and Island Dairy SCAN sites, Hawaii}

Two COSMOS probes were installed on the northeastern slopes of Mauna Kea in June 2010, at two sites that are part of the Soil Climate Analysis Network (SCAN) operated by the US Department of Agriculture (Schaefer et al., 2007). The Island Dairy probe is in a humid climate near the coast in a pasture near sea level. The Silver Sword probe is on the slope of the mountain in a mixed terrain of lava flows and volcanic ash at $\sim 2900 \mathrm{~m}$. This second probe is above the thermal inversion in a dry climate and sees limited rain from the trade winds.

Soil moisture derived from fast neutrons (Fig. 15b and e) is compared with precipitation data (Fig. 15a and d) and soil moisture records from SCAN (Fig. $15 \mathrm{c}$ and f). Measurements at these two sites are distinctly different. At Silver Sword (Fig. 15a-c) the soil is dry in the summer and becomes wet in November, whereas at Island Dairy (Fig. 15d-f) the soil is wet all the time. This pattern is expected based on the difference in precipitation patterns at these sites. The trade winds generate precipitation throughout the year at the coastal site, but a thermal inversion at approximately $2000 \mathrm{~m}$ locks tradewind moisture below the high-elevation site, and this mountain site remains dry in summer. In winter, cold fronts bring high level clouds and precipitation at all altitudes, thus maintaining the high soil moisture level at the low-elevation site and also increasing soil moisture at the high-altitude site.

The COSMOS data are more noisy than the SCAN data, which is almost entirely due to counting statistics of neutrons. At Silver Sword the count rate for fast neutrons is $\sim 3000$ counts per hour, which results in the counting uncertainty of $0.6 \%$ on 12 -h average values. At Island Dairy the COSMOS data are much more noisy. This is due to much lower count rate here, $\sim 400$ counts per hour, which results in the counting uncertainty of $1.5 \%$ on 12-hr averages. Four factors contribute to this low count rate and the correspondingly large uncertainties (Sect. 2.6): (1) low latitude and low elevation (Sect. 2.1), (2) high atmospheric water vapor (Sect. 2.5.1), (3) high lattice water (Sect. 2.3.1; Table 2), and (4) high soil moisture. Additional filtering could produce a smoother time series, but would also have negative effects,
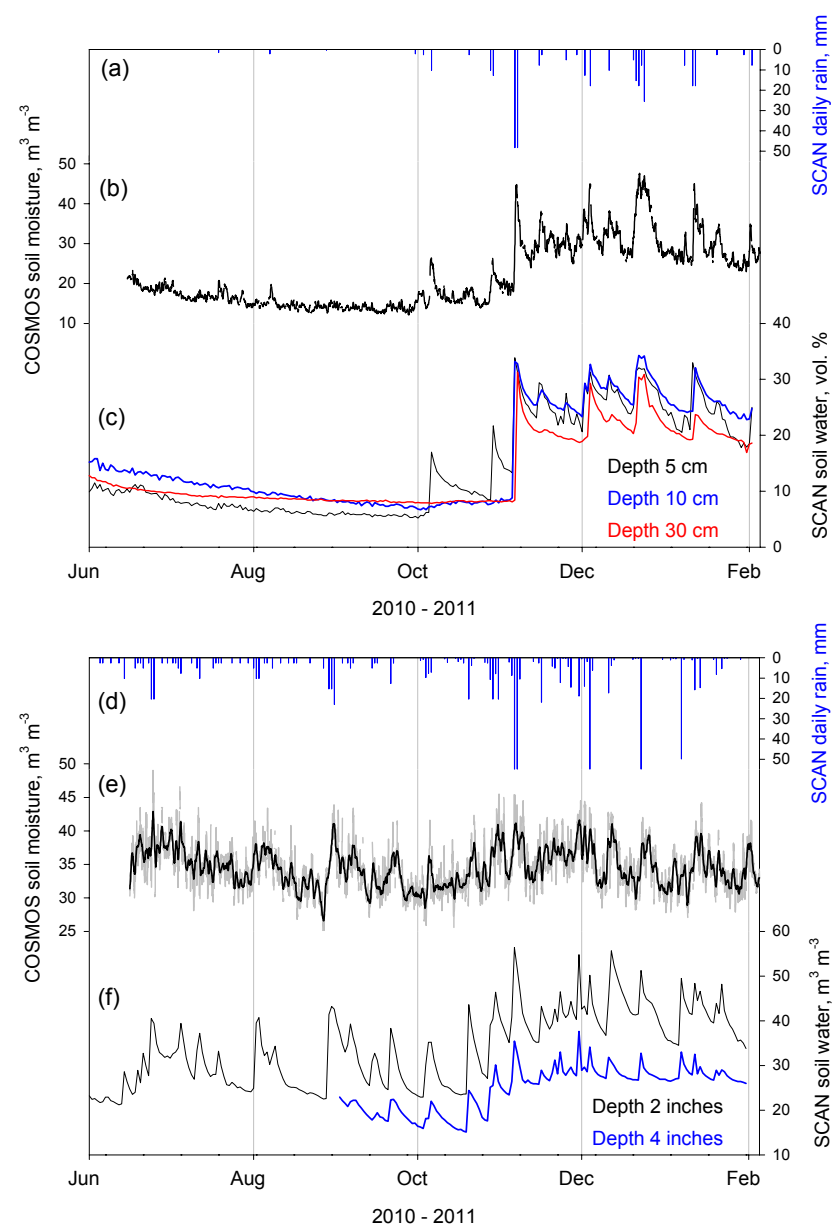

Fig. 15. (a) Precipitation from $\operatorname{SCAN}(\mathbf{a}, \mathbf{d})$, neutron-derived soil moisture (b, e), and soil water content from $\operatorname{SCAN}(\mathbf{c}, \mathbf{f})$ for two sites on the Island of Hawaii: Silver Sword (a-c) and Island Dairy (d-f). SCAN, Soil Climate Analysis Network, is operated by the United States Department of Agriculture (USDA).

such as reduced amplitude of variations and reduced temporal resolution. This example illustrates the inherent limitations of the cosmic-ray method under a combination of unfavorable conditions.

\section{Appendix A}

\section{Data levels}

Level 1 data contains raw counts of fast and thermal neutrons as well as probe diagnostics for quality control purposes. Neutrons are counted over a user-set time period (usually one hour) and count levels are reported at the end of each period. An example of Level 1 data is in the table below (from the Sevilleta New Grass site in New Mexico). 


\begin{tabular}{lcccccc}
\hline $\begin{array}{l}\text { DD-MM-YYYY, HH:MM } \\
\text { [UTC] }\end{array}$ & $\begin{array}{c}\text { MOD } \\
{\left[\mathrm{h}^{-1}\right]}\end{array}$ & $\begin{array}{c}\text { UNMO } \\
{\left[\mathrm{h}^{-1}\right]}\end{array}$ & $\begin{array}{c}\text { PRESS } \\
{[\mathrm{mb}]}\end{array}$ & $\begin{array}{c}\text { TEM } \\
{[\mathrm{C}]}\end{array}$ & $\begin{array}{c}\text { RH } \\
{[\%]}\end{array}$ & $\begin{array}{c}\text { BATT } \\
{[\mathrm{V}]}\end{array}$ \\
\hline 26 Feb 2011, 17:48 & 3409 & 1585 & 837.8 & 12 & 8 & 14.5 \\
\hline
\end{tabular}

In the table, MOD is moderated (fast neutrons) count rate; UNMO is thermal neutron count rate; PRESS is pressure inside the probe box (the same as outside pressure); TEM is temperature inside the box (not the same as outside temperature); RH is relative humidity inside the box (not the same as outside humidity); and BATT is the battery voltage. Level 1 data can be accessed by first selecting the probe on the COSMOS main map, then selecting "Level 1 Data" link or "Plots" link.

Level 2 data are produced by converting the raw data from Level 1 to a format suitable for soil moisture computation. Level 2 data are quality controlled to remove data points that are deemed outliers or otherwise problematic (the criteria are described on the COSMOS web site: http://cosmos.hwr.arizona.edu/Docs/data.txt). Qualitycontrolled fast (moderated) counts are converted to standard counts to remove local effects. Standard counts are directly comparable among all sites. For standard counts we use the first probe, located in San Pedro, Arizona. An example of Level 2 data, corresponding to Level 1 data in the table above, is shown in the table below.

\begin{tabular}{llllccccccc}
\hline $\begin{array}{l}\text { DD-MM-YYYY, HH:MM } \\
\text { [UTC] }\end{array}$ & $\begin{array}{l}\text { MOD } \\
{\left[\mathrm{h}^{-1}\right]}\end{array}$ & $\begin{array}{c}\text { PROBE } \\
{[-]}\end{array}$ & $\begin{array}{c}\text { PRESS } \\
{[\mathrm{mb}]}\end{array}$ & $\begin{array}{c}\text { SCALE } \\
{[-]}\end{array}$ & $\begin{array}{c}\text { SANPE } \\
{[-]}\end{array}$ & $\begin{array}{c}\text { INTEN } \\
{[-]}\end{array}$ & $\begin{array}{c}\text { VAPOR } \\
{[-]}\end{array}$ & $\begin{array}{c}\text { OTHER } \\
{[-]}\end{array}$ & $\begin{array}{c}\text { CORR } \\
{\left[\mathrm{h}^{-1}\right]}\end{array}$ & $\begin{array}{c}\text { ERR } \\
{\left[\mathrm{h}^{-1}\right]}\end{array}$ \\
\hline
\end{tabular}

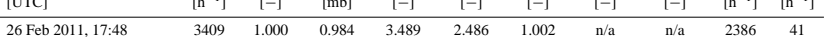

In the table, MOD is moderated (fast) neutron count rate (the same as in Level 1); PROBE is the scaling factor that accounts for different probe designs (currently, there are four types of probes in the COSMOS); PRESS is pressure scaling factor that accounts for temporal changes in local pressure; SCALE is the scaling factor accounting for effects of local altitude and geomagnetic latitude (geomagnetic field strength), computed using equations in Desilets and Zreda (2003); SANPE is the scaling factor SCALE for the San Pedro site; INTEN is the scaling factor accounting for temporal changes in the incoming cosmic-ray intensity, computed using neutron monitor data (currently from the Jungfraujoch neutron monitor in Switzerland, data from www.nmdb.eu); VAPOR is the scaling factor for atmospheric water vapor; OTHER is the placeholder for any future corrections; and CORR is the probe count rate corrected for all the scaling factors, computed as

$$
\begin{aligned}
\text { CORR }= & (\text { MOD } \cdot \text { PROBE } \cdot \text { PRESS } \cdot \text { SANPE } \\
& \cdot \text { VAPOR } \cdot \text { OTHER }) /(\text { SCALE } \cdot \text { INTEN }) ;
\end{aligned}
$$

and ERR is the uncertainty based on the counting statistics, computed as square root of the original count rate (MOD), rescaled to CORR (Eq. A1):

$$
\mathrm{ERR}=\mathrm{CORR} / \mathrm{MOD}^{0.5} \text {. }
$$

Level 3 data are produced by converting the quality controlled, corrected Level 2 data to soil moisture using a calibration equation (we use Eq. 4). An example of Level 3 data, corresponding to Level 1 and Level 2 data in the tables above, is shown in the table below.

\begin{tabular}{lcccc}
\hline $\begin{array}{l}\text { DD-MM-YYYY, HH:MM } \\
\text { [UTC] }\end{array}$ & $\begin{array}{c}\text { SOILM } \\
{[\%]}\end{array}$ & $\begin{array}{c}\text { DEP } \\
{[\mathrm{cm}]}\end{array}$ & $\begin{array}{c}\text { SM12H } \\
{[\%]}\end{array}$ & $\begin{array}{c}\text { D12 } \\
{[\mathrm{cm}]}\end{array}$ \\
\hline 26 Feb 2011, 17:48 & 9.9 & 28 & 9.0 & 29 \\
\hline
\end{tabular}

In the table, SOILM is soil moisture for the counting time interval (we use $1 \mathrm{~h}$ ), in either volumetric units (\% by volume, or $\mathrm{cm}^{3}$ of water per $\mathrm{cm}^{3}$ of soil) or gravimetric units (\% by weight, or $\mathrm{g}$ of water per $\mathrm{g}$ of dry soil) depending on how the calibration was done; DEP is the estimated effective measurement depth (or thickness over which the soil moisture was measured; Franz et al., 2012a); SM12H is a 12-h running average, computed using a 12-h robust boxcar filter; and D12 is the corresponding effective measurement depth for SM12H.

Level 4 data will be added in the future. COSMOS data will be assimilated into a land-surface model to produce soil moisture profiles that will be available as Level 4 data at all probe locations in near-real time.

Acknowledgements. The COSMOS project is funded by the Atmospheric Science, Hydrology, and Ecology Programs of the US National Science Foundation (grant ATM-0838491). The initial research that lead to the development of the cosmic-ray soil moisture method and probe was supported by the David and Lucile Packard Foundation (Fellowship for Science and Engineering 95-1832). Ensuing systematic work was supported by the US National Science Foundation (grants EAR-0001191, EAR-0126209, EAR-0126241, EAR-0345440, and EAR-0636110) and the Army Research Office (grant 43857-EV). We thank those who contributed in various ways to the COSMOS project: Gary Womack, Quaesta Corporation; Pete Shifflett, Zetetic Institute; Ken Cummins, University of Arizona; Sharon Desilets, Albuquerque; Dave Gochis, NCAR; Tyson Ochsner, Oklahoma State University; Patrick Niemeyer and Mike Cosh, USDA; and students at Arizona and other institutions. Paul Ferre has read an early version of this manuscript. We acknowledge the NMDB database (www.nmdb.eu), founded under the European Union's FP7 programme (contract no. 213007) for providing data from the monitor Jung, supported by the Physikalisches Institut of the University of Bern and by the International Foundation High Altitude Research Stations Jungfraujoch, Bern, Switzerland (http://cosray.unibe.ch/).

Edited by: H.-J. Hendricks Franssen 


\section{References}

Anton, F., Paul, W., Mampe, W., Paul, L., and Paul, S.: Measurement of the neutron lifetime by magnetic storage of free neutrons, Nucl. Instrum. Meth. A, 284, 101-107, 1989.

Bethe, H. A., Korff, S. A., and Placzek, G.: On the interpretation of neutron measurements in cosmic radiation, Phys. Rev., 57, 573$587,1940$.

Bogena, H. R., Herbst, M., Huisman, J. A., Rosenbaum, U., Weuthen, A., and Vereecken, H.: Potential of wireless sensor networks for measuring soil water content variability, Vadose Zone J., 9, 1002-1013, 2010.

Carlson, P.: A century of cosmic rays, Phys. Today, 65, 30-36, 2012.

Compton, A. H. and Eastman, G.: Cosmic rays, Nature, 135, 695698, 1935.

Desilets, D. and Zreda, M.: Spatial and temporal distribution of secondary cosmic-ray nucleon intensities and applications to in-situ cosmogenic dating, Earth Planet. Sc. Lett., 206, 21-42, 2003.

Desilets, D., Zreda, M., and Prabu, T.: Extended scaling factors for in situ cosmogenic nuclides: New measurements at low latitude, Earth Planet. Sc. Lett., 246, 265-276, 2006.

Desilets, D., Zreda, M., and Ferre, T.: Nature's neutron probe: Landsurface hydrology at an elusive scale with cosmic rays, Water Resour. Res., 46, W11505, doi:10.1029/2009WR008726, 2010.

Entekhabi, D., Njoku, E., Houser, P., Spencer, M., Doiron, T., Smith, J., Girard, R., Belair, S., Crow, W., Jackson, T., Kerr, Y., Kimball, J., Koster, R., McDonald, K., O’Neill, P., Pultz, T., Running, S., Shi, J. C., Wood, E., and van Zyl, J.: The Hydrosphere State (HYDROS) mission concept: An Earth system pathfinder for global mapping of soil moisture and land freeze/thaw, IEEE T. Geosci. Remote, 42, 2184-2195, 2004.

Entin, J. K., Robock, A., Vinnikov, K. Y., Hollinger, S. E., Liu, S., and Namkhai, A.: Temporal and spatial scales of observed soil moisture variations in the extratropics, J. Geophys. Res., 105, 11865-11878, 2000.

Famiglietti, J. S., Devereaux, J. A., Laymon, C. A., Tsegaye, T., Houser, P. R., Jackson, T. J., Graham, S. T., Rodell, M., and van Oevelen, P. J.: Ground-based investigation of soil moisture variability within remote sensing footprints during the Southern Great Plains 1997 (SGP97) Hydrology Experiment, Water Resour. Res., 35, 1839-1852, 1999.

Famiglietti, J. S., Ryu, D., Berg, A. A., Rodell, M., and Jackson, T. J.: Field observations of soil moisture variability across scales, Water Resour. Res., 44, W01423, doi:10.1029/2006WR005804, 2008.

Fermi, E.: Artifical radioactivity produced by neutron bombardment, http://www.nobelprize.org/nobel_prizes/physics/laureates/ 1938/fermi-lecture.pdf, last access: 3 November 2012, Nobel Lectures, Physics 1922-1941, Elsevier Publishing Company, Amsterdam, 1965, 414-421, 1938.

Franz, T. E., Zreda, M., Ferre, T. P. A., Rosolem, R., Zweck, C., Stillman, S., Zeng, X., and Shuttleworth, W. J.: Measurement depth of the cosmic-ray soil moisture probe affected by hydrogen from various sources, Water Resour. Res., 48, W08515, doi:10.1029/2012WR011871, 2012a.

Franz, T. E., Zreda, M., Rosolem, R., and Ferre, T. P. A.: A universal calibration function for determination of soil moisture with cosmic-ray neutrons, Hydrol. Earth Syst. Sci. Discuss., 9, 10303-10322, doi:10.5194/hessd-9-10303-2012, 2012b.
Franz, T. E., Zreda, M., Rosolem, R., and Ferre, T. P. A.: Field validation of cosmic-ray soil moisture probe using a distributed sensor network, Vadose Zone J., doi:10.2136/vzj2012.0046, in press, 2012c.

Gardner, W. H.: Water content, in: Methods of soil analysis: Part 1, Physical and Mineralogical methods, edited by: Klute, A., American Society of Agronomy, Madison, 493-544, 1986.

Gardner, W. and Kirkham, D.: Determination of soil moisture by neutron scattering, Soil Sci., 73, 391-401, 1952.

Geiger, K. W.: Evaporation neutrons from cosmic ray nuclear interactions in various elements, Can. J. Phys., 34, 288-303, 1956.

Glasstone, S. and Edlund, M. C.: Elements of nuclear reactor theory, 5th Edn., Van Nostrand, New York, 416 pp., 1952.

Hendrick, L. D. and Edge, R. D.: Cosmic-ray neutrons near the Earth, Phys. Rev. Ser. II, 145, 1023-1025, 1966.

Hess, V. F.: Uber Beobachtungen der durchdringenden Strahlung bei sieben Freiballonfahrten, Physikalische Z., 13, 1084-1091, 1912.

Hess, W. N., Patterson, H. W., and Wallace, R.: Cosmic-ray neutron energy spectrum, Phys. Rev., 116, 445-457, 1959.

Hillel, D.: Environmental soil physics, Academic Press, Amsterdam, 771 pp., 1998.

Hornbuckle, B., Irvin, S., and Patton, J.: The impact of rapidly growing vegetation on COSMOS soil moisture measurements, Abstract presented at 2011 Soil Science Society of America Annual Meeting, San Antonio, Texas, 2011.

Knoll, G. F.: Radiation detection and measurement, Wiley, New York, 802 pp., 2000.

Kodama, M., Nakai, K., Kawasaki, S., and Wada, M.: Application of cosmic-ray neutron measurements to the determination of the snow-water equivalent, J. Hydrol., 41, 85-92, 1979.

Kodama, M., Kudo, S., and Kosuge, T.: Application of atmospheric neutrons to soil moisture measurement, Soil Sci., 140, 237-242, 1985.

Krane, K. S.: Introductory nuclear physics, Wiley, New York, 845 pp., 1988.

Larson, K. M., Small, E. E., Gutmann, E., Bilich, A. L., Braun, J. J., and Zavorotny, V. U.: Use of GPS receivers as a soil moisture network for water cycle studies, Geophys. Res. Lett., 35, L24405, doi:10.1029/2008GL036013, 2008.

Moraal, H., Caballero-Lopez, R. A., McCracken, K. G., and Humble, J. E.: The influence of cosmic-ray modulation at high heliospheric latitudes on the solar diurnal variation observed at earth, Astrophys. J., 629, 556-560, 2005.

Njoku, E. G. and Entekhabi, D.: Passive microwave remote sensing of soil moisture, J. Hydrol., 184, 101-129, 1996.

Pelowitz, D. B.: MCNPX user's manual, version 5, LA-CP-050369, Los Alamos National Laboratory, Los Alamos, 2005.

Rasmussen, R., Baker, B., Kochendorfer, J., Meyers, T., Landolt, S., Fischer, A. P., Black, J., Thériault, J. M., Kucera, P., Gochis, D., Smith, C., Nitu, R., Hall, M., Ikeda, K., and Gutmann, E.: How well are we measuring snow: The NOAA/FAA/NCAR winter precipitation test bed, B. Am. Meteorol. Soc., 93, 811-=829, 2012.

Rivera Villarreyes, C. A., Baroni, G., and Oswald, S. E.: Integral quantification of seasonal soil moisture changes in farmland by cosmic-ray neutrons, Hydrol. Earth Syst. Sci., 15, 3843-3859, doi:10.5194/hess-15-3843-2011, 2011. 
Robinson, D. A., Campbell, C. S., Hopmans, J. W., Hornbuckle, B. K., Jones, S. B., Knight, R., Ogden, F., Selker, J., and Wendroth, O.: Soil moisture measurement for ecological and hydrological watershed-scale observatories: A review, Vadose Zone J., 7, 358389,2008

Schaefer, G. L., Cosh, M. H., and Jackson, T. J.: The USDA Natural Resources Conservation Service Soil Climate Analysis Network (SCAN), J. Atmos. Ocean. Tech., 24, 2073-2077, 2007.

Sears, V. F.: Neutron scattering lengths and cross sections, Neutron News, 3, 26-37, 1992.

Simpson, J. A.: The cosmic ray nucleonic component: The invention and scientific uses of the neutron monitor - (Keynote Lecture), Space Sci. Rev., 93, 11-32, 2000.

Simpson, J. A. and Uretz, R. B.: Cosmic-ray neutron production in elements as a function of latitude and altitude, Phys. Rev., 90, 44-50, 1953.

Smart, D. F. and Shea, M. A.: Geomagnetic cutoff rigidity computer program: Theory, software description and example, NAG5-8009, http://ccmc.gsfc.nasa.gov/modelweb/sun/ cutoff.html, last access: 3 November 2012, The University of Alabama, Huntsville, Alabama, USA, 2001.
Steele-Dunne, S. C., Rutten, M. M., Krzeminska, D. M., Hausner, M., Tyler, S. W., Selker, J., Bogaard, T. A., and van de Giesen, N. C.: Feasibility of soil moisture estimation using passive distributed temperature sensing, Water Resour. Res., 46, W03534, doi:10.1029/2009WR008272, 2010.

Western, A. W. and Blöschl, G.: On the spatial scaling of soil moisture, J. Hydrol., 217, 203-224, 1999.

Western, A. W., Grayson, R. B., and Blöshl, G.: Scaling of soil moisture: A hydrologic perspective, Ann. Rev. Earth Planet. Sc., 30, 149-180, 2002.

Zreda, M., Desilets, D., Ferré, T. P. A., and Scott, R. L.: Measuring soil moisture content non-invasively at intermediate spatial scale using cosmic-ray neutrons, Geophys. Res. Lett., 35, L21402, doi:10.1029/2008GL035655, 2008.

Zreda, M., Zeng, X., Shuttleworth, J., Zweck, C., Ferre, T., Franz, T., Rosolem, R., Desilets, D., Desilets, S., and Womack, G.: Cosmic-ray neutrons, an innovative method for measuring areaaverage soil moisture, GEWEX News, 21, 6-10, 2011. 